\title{
Article \\ Mesenchymal Stromal Cell Differentiation for Generating Cartilage and Bone-Like Tissues In Vitro
}

\author{
Graziana Monaco $^{1,2}$, Yann D. Ladner ${ }^{1,3}{ }^{\mathbb{D}}$, Alicia J. El Haj ${ }^{4}$, Nicholas R. Forsyth ${ }^{2} \mathbb{D}$, Mauro Alini $^{1} \mathbb{D}$ \\ and Martin J. Stoddart $1,2, * \mathbb{D}$
}

1 AO Research Institute Davos, Regenerative Orthopaedics Program, 7270 Davos Platz, Switzerland; graziana.monaco@aofoundation.org (G.M.); yann.ladner@aofoundation.org (Y.D.L.); mauro.alini@aofoundation.org (M.A.)

2 Guy Hilton Research Centre, School of Pharmacy and Bioengineering, Keele University, Stoke-on-Trent, Staffordshire ST4 7QB, UK; n.r.forsyth@keele.ac.uk

3 Institute for Biomechanics, ETH Zurich, Lengghalde 5, CH-8008 Zurich, Switzerland

4 Healthcare Technology Institute, Institute of Translational Medicine, University of Birmingham, Birmingham B15 2TT, UK; A.ElHaj@Bham.ac.uk

* Correspondence: martin.stoddart@aofoundation.org

Citation: Monaco, G.; Ladner, Y.D.; El Haj, A.J.; Forsyth, N.R.; Alini, M.; Stoddart, M.J. Mesenchymal Stromal Cell Differentiation for Generating Cartilage and Bone-Like Tissues In Vitro. Cells 2021, 10, 2165. https:// doi.org/10.3390/cells10082165

Academic Editors: Karina

Theresa Wright and Charlotte Hulme

Received: 9 June 2021

Accepted: 18 August 2021

Published: 22 August 2021

Publisher's Note: MDPI stays neutral with regard to jurisdictional claims in published maps and institutional affiliations.

Copyright: (c) 2021 by the authors. Licensee MDPI, Basel, Switzerland. This article is an open access article distributed under the terms and conditions of the Creative Commons Attribution (CC BY) license (https:// creativecommons.org/licenses/by/ $4.0 /)$.

\begin{abstract}
In the field of tissue engineering, progress has been made towards the development of new treatments for cartilage and bone defects. However, in vitro culture conditions for human bone marrow mesenchymal stromal cells (hBMSCs) have not yet been fully defined. To improve our understanding of cartilage and bone in vitro differentiation, we investigated the effect of culture conditions on hBMSC differentiation. We hypothesized that the use of two different culture media including specific growth factors, TGF $\beta 1$ or BMP2, as well as low $\left(2 \% \mathrm{O}_{2}\right)$ or high $\left(20 \% \mathrm{O}_{2}\right)$ oxygen tension, would improve the chondrogenic and osteogenic potential, respectively. Chondrogenic and osteogenic differentiation of hBMSCs isolated from multiple donors and expanded under the same conditions were directly compared. Chondrogenic groups showed a notable upregulation of chondrogenic markers compared with osteogenic groups. Greater sGAG production and deposition, and collagen type II and I accumulation occurred for chondrogenic groups. Chondrogenesis at $2 \% \mathrm{O}_{2}$ significantly reduced ALP gene expression and reduced type I collagen deposition, producing a more stable and less hypertrophic chondrogenic phenotype. An $\mathrm{O}_{2}$ tension of $2 \%$ did not inhibit osteogenic differentiation at the protein level but reduced ALP and OC gene expression. An upregulation of ALP and OC occurred during osteogenesis in BMP2 containing media under $20 \% \mathrm{O}_{2}$; $\mathrm{BMP} 2$ free osteogenic media downregulated ALP and also led to higher sGAG release. A higher mineralization was observed in the presence of BMP2 during osteogenesis. This study demonstrates how the modulation of $\mathrm{O}_{2}$ tension, combined with tissue-specific growth factors and media composition can be tailored in vitro to promote chondral or endochondral differentiation while using the same donor cell population.
\end{abstract}

Keywords: osteogenesis; chondrogenesis; donor comparison; osteochondral constructs

\section{Introduction}

Cartilage and bone are unique and complex tissues, in physical proximity to each other but very different in structure, function, cell phenotype, microenvironment and mechanical stiffness. Bone and cartilage together form the osteochondral unit, which provides the structure and support necessary for load-bearing and movement. Damage to either of these tissues, caused by trauma or diseases such as osteoarthritis, reduces function, eventually leading to joint immobility and severe pain [1,2]. Depending on the nature, size and location of the osteochondral lesion, invasive surgical treatments are often required [3,4], including osteochondral grafts and mosaicplasty [5,6]. As an alternative, cell-based regenerative approaches such as autologous chondrocyte implantation (ACI) [7] 
or matrix assisted ACI [8] have been developed. However, the difficulties in first repairing the bone prior to applying ACI, joint orthofibrosis, and suboptimal osteochondral tissue structure, combined with the limited supply of donor tissue and, hence, low number of donor chondrocytes, can present significant clinical hurdles [9].

The limitations of autologous transplantation have heightened interest in the development of new tissue-engineering approaches for the treatment of cartilage and bone defects, separately, or as a combined osteochondral unit. Tissue-engineered approaches, that are mainly based on the use of cells with a scaffold carrier, aim to produce in vitro an autologous patient-tailored graft to restore osteochondral damage without the need for tissue harvesting $[10,11]$. The cell type used is a critical element that drives tissue repair or regeneration, both in vitro and in vivo after implantation. Several tissue-engineering strategies use primary chondrocytes, since this cell-type has the ability to create and maintain the desired tissue with positive outcomes [12,13]. However, to avoid sacrificing further cartilage tissue, other readily available sources need to be considered. One solution could be the use of primary autologous human bone marrow derived mesenchymal stromal cells (hBMSCs) [14]. hBMSCs can be easily harvested and isolated from bone marrow aspirates without the creation of a second cartilage injury, and since the cells belong to the same patient for whom the therapy is intended, there are no issues relating to rejection. Besides these advantages, hBMSCs are the best described, the most advanced in clinical use and, most importantly, have the ability to undergo both chondrogenic and osteogenic differentiation [15-17]. In addition, MSCs also overcome the problem of low donor cell number, as they maintain multilineage potential following expansion, allowing a sufficient cell number for engineered tissues to be achieved $[14,18,19]$. Thus, hBMSCs are an attractive cell source for osteochondral tissue engineering starting from a single batch of easily harvested and expanded autologous cells [20-23].

Different strategies have been attempted to engineer osteochondral tissue in vitro using MSCs. Usually, the osteochondral composite consists of a bone construct underlying a cartilage construct. In accordance with the classification proposed by Martin et al., osteochondral constructs have been generated using: (1) scaffolds for the bone zone with a scaffold-free approach for cartilage zone; or (2) the scaffolds for bone and cartilage are combined at the time of the implantation, or (3) a single heterogeneous composite, or (4) a single homogeneous scaffold for both zones [10].

The variety of models so far investigated highlight that despite significant advances in this area, a better understanding of the factors controlling MSC fate in the process of cartilage and bone formation will be crucial. Modulation of these factors could lead to a more stable and long-lasting tissue. This is particularly true when aiming for chondrogenic differentiation, where a key limitation exists due to MSC hypertrophy that can lead to bone formation instead of stable hyaline cartilage [24-26]. Appropriate environmental stimuli that can stabilize the articular chondrocyte phenotype have been studied and low oxygen tension ranging from $2 \% \mathrm{O}_{2}$ to $5 \% \mathrm{O}_{2}$ has been proposed to suppress cartilage hypertrophy [27-29]. This could relate to the similar oxygen tension found in vivo within articular cartilage, which ranges between $1 \%$ to $4 \%$. However, cartilage and bone require different oxygen tensions and the development of an osteochondral composite by simultaneously exposing the cells to two different oxygen levels, requires a complex system that is not universally available [30]. Alternatively, the development of a single osteochondral unit requires the use of a unique culture media capable of successfully addressing MSC chondrogenic and osteogenic differentiation simultaneously. To the best of our knowledge, a unique culture media with these characteristics has not yet been developed

Therefore, we developed in parallel, separate in vitro constructs for bone and cartilage from the same passage of hBMSCs, with the approach to combine the two tissues at the time of the implantation. Due to donor variation, we believe it is crucial to study the various combinations on the same donor-derived cell source in parallel.

hMSCs seeded in fibrin:polyurethane scaffolds were treated with either chondrogenic culture media supplemented with TGF $\beta 1$ [31] or osteogenic differentiation media with 
or without bone morphogenic protein 2 (BMP2) [32]. Additionally, low and high oxygen conditions were compared.

We hypothesized that a cell-type-specific culture media, associated with the most suitable oxygen tension can be helpful in providing the right stimuli for more stable hBMSC chondrogenic and osteogenic differentiation from the same cell population. The overall aim of this study was to investigate the influence on culture conditions on chondrogenesis and osteogenesis from the same population of monolayer-expanded cells and characterize the different phenotypes that develop.

\section{Materials and Methods}

\subsection{Poly(Ester-Urethane) Scaffold Preparation}

Poly(ester-urethane) porous scaffolds (PU macroporosity ranging from 90 to $300 \mu \mathrm{m}$ ) were prepared using hexamethylene diisocyanate, poly (1-caprolactone) diol and isosorbide diol (1,4: 3,6-dianhydro-D-sorbitol) via a salt leaching-phase inverse technique [33]. The PU scaffold was cut by water-jet (CUTEC AG, Basel, Switzerland) producing cylindrical scaffolds ( $8 \mathrm{~mm}$ dimeter $\times 2 \mathrm{~mm}$ height) sterilized in a cold cycle at $37^{\circ} \mathrm{C}$ via ethylene oxide process and degassed under vacuum for six days before use.

\subsection{Isolation of Human Bone Marrow Derived MSCs}

Bone marrow was obtained with full ethical approval (KEK-ZH-NR: 2010-0444/0) and the written consent from patients undergoing routine operations due to bone fracture. MSCs were isolated from four different marrow aspirates (one female 25-year old and three males 19, 50 and 66 years old) using Ficoll density separation (Sigma-Aldrich, Buchs, Switzerland).

Mononuclear cells were collected from the interphase seeded at a density of 50,000 cells $/ \mathrm{cm}^{2}$ in alpha-minimum essential medium ( $\alpha$ MEM) (Gibco, Carlsbad, CA, USA), 10\% MSC tested Fetal Bovine serum (FBS) (Pan Biotech, Aidenbach, Germany), $5 \mathrm{ng} / \mathrm{mL}$ basic fibroblast growth factor (bFGF) (Peprotech, Rocky Hill, CN, USA) and 1\% penicillin/streptomycin (Gibco). Media was refreshed after $96 \mathrm{~h}$. The cells were passaged when $70 \%$ confluent and seeded at a cell density of 3000 cells $/ \mathrm{cm}^{2}$. The chondrogenic potential of each donor was confirmed using standard techniques. hBMSCs isolated from each donor were used separately in four independent experiments.

\subsection{Scaffold Seeding and Chondrogenic Differentiation}

hMSCs at passage 3 were trypsinized, suspended in $75 \mu \mathrm{L}$ of fibrinogen-thrombinsolution and seeded in cylindrical $(8 \mathrm{~mm} \times 2 \mathrm{~mm}$ ) macroporous polyurethane (PU) scaffolds (fibrin provided by Baxter, Vienna, Austria) [34]. The number and distribution of the cells in each scaffold varied by group: (1) the scaffolds intended for osteogenic differentiation were evenly seeded with a cell density of $2 \times 10^{6}$ cells $/ 75 \mu \mathrm{L}$ fibrinogen-thrombinsolution; (2) the scaffolds intended for chondrogenic differentiation were asymmetrically seeded in two steps: first, $3 \times 10^{6}$ cells $/ 75 \mu \mathrm{L}$ fibrinogen-thrombin-solution were evenly seeded within the scaffold, then 500,000 hMSCs were resuspended in $100 \mu \mathrm{L}$ of culture media and allowed to adhere to the upper surface of the scaffold in the incubator at $37^{\circ} \mathrm{C}$ for one hour [34,35].

To achieve chondrogenic differentiation, constructs were kept in high glucose DMEM, $1 \%$ Insulin-Transferrin-Selenium (ITS), $1 \%$ Penicillin/Streptomycin, $1 \%$ non-essential amino acid, $50 \mu \mathrm{g} / \mathrm{mL}$ ascorbate-2-phosphate, $5 \mu \mathrm{M} \varepsilon$-amino-caproic acid (EACA), $10^{-7} \mathrm{M}$ dexamethasone and $10 \mathrm{ng} / \mathrm{mL}$ TGF- $\beta 1$ (Fitzgerald, Acton, MA, USA).

To achieve osteogenic differentiation, constructs were kept in low glucose DMEM supplemented with $1 \%$ Pen/Strep, $50 \mu \mathrm{g} / \mathrm{mL}$ ascorbate-2-phosphate, $5 \mu \mathrm{M} \varepsilon$-amino-caproic acid (EACA), $10 \mathrm{nM}$ dexamethasone, $5 \mathrm{mM} \beta$-glycerol phosphate, $10 \%$ Fetal Bovine serum. In an additional group, $100 \mathrm{ng} / \mathrm{mL}$ Chinese hamster ovary (CHO) derived BMP2 was added to the osteogenic culture media. 
Constructs were exposed to either high $\left(20 \% \mathrm{O}_{2}\right)$ or low oxygen $\left(2 \% \mathrm{O}_{2}\right)$ using a small hypoxia chamber (BioSpherix, ProOx Model C21) that allowed for fast recovery of low oxygen tension every time the chamber was opened. The scaffold constructs were incubated for 14 days as described in the graphical abstract. The culture medium was changed every second day, and conditioned medium was collected three times per week for biochemical analysis. Prior to each media change, the media was conditioned to $2 \% \mathrm{O}_{2}$ to minimize the $\mathrm{O}_{2}$ variation where required. A full experimental schematic is presented in Figure 1.

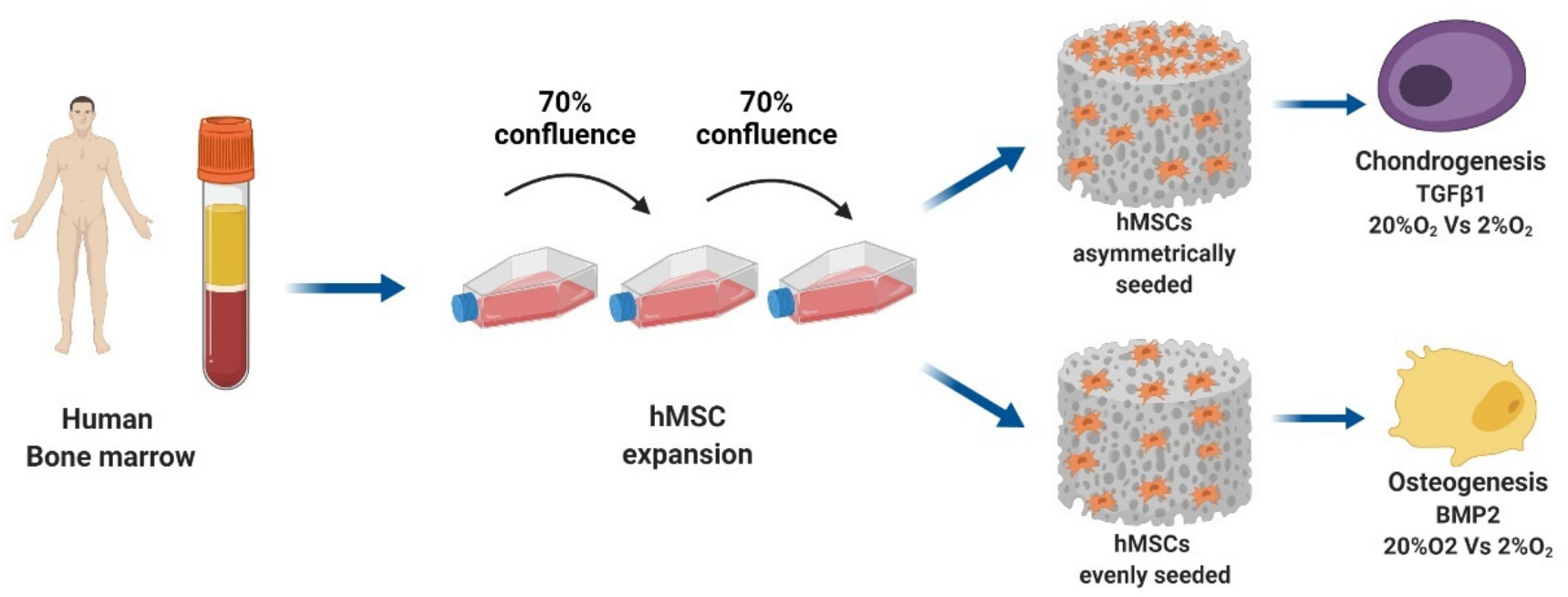

Figure 1. Schematic overview of the experimental design. Created with BioRender.com.

\subsection{Gene Expression Analysis: RNA Isolation, cDNA Synthesis, Real Time qPCR}

After 14 days of culture, constructs were harvested and total RNA was isolated using TRI Reagent (Molecular Research Centre Inc, Cincinnati, OH, USA). Total RNA was isolated at day 0 to assess basal gene expression levels.

TaqMan reverse transcription was then performed using $1 \mu \mathrm{g}$ of total RNA, random hexamer primers and TaqMan reverse transcription reagents (Applied Biosystems, Carlsbad, CA, USA). Real-time PCR was performed using the QuantStudio 6 Flex real-time PCR system (Applied Biosystems). A panel of human genes associated with chondrogenic markers (COL2A1, ACAN, SOX9), the hypertrophic marker, COL10A1 and osteogenic markers (RUNX2; ALP; OC) were investigated.

Primers for RPLP0, COL2A1, COL10A1, ACAN, RUNX2, VEGF and OC mRNA were synthesized by Microsynth AG (Balgach, Switzerland) (Table 1). Primers for SOX9, SRY (sex determining region Y)-box 9 cartilage transcription factor (Hs00165814_m1), HIF1 $\alpha$ (Hs00153153_m1) and ALP, alkaline phosphatase (Hs00758162_m1) were purchased as assays on demand from Applied Biosystems (Warrington, UK).

Relative quantification of target mRNA was determined according to the comparative CT method with hRPLP0 as endogenous control. In addition, the level of gene expression for each gene was determined relative to day 0 monolayer via a $\Delta \Delta C T$ comparison.

\subsection{Sulphated Glycosaminoglycans and DNA Quantification}

After 14 days of culture, constructs were digested with $1 \mathrm{~mL}$ proteinase $\mathrm{K} 0.5 \mathrm{mg} / \mathrm{mL}$ at $56{ }^{\circ} \mathrm{C}$ for $16 \mathrm{~h}$. After digestion, total DNA content was measured spectrofluorometrically using Bisbenzimide Hoechst 33,258 dye (Polysciences Inc., Warrington, PA, USA) with purified calf-thymus DNA, as standard (Lubio Science, Luzern, Switzerland) [36].

Sulphated glycosaminoglycan (GAG) retained within the scaffolds was determined by the dimethylmethylene blue-dye method (Sigma-Aldrich, Buchs, Switzerland) at pH 3 , using bovine chondroitin 4-sulfate sodium salt from bovine trachea (Fluka, St. Louis, MO, 
USA) [37]. The total GAG content of the culture media was also measured to estimate the release of matrix molecules from the constructs.

Table 1. Human oligonucleotide primers and probes used for qRT-PCR.

\begin{tabular}{|c|c|c|c|}
\hline Gene & Primer Forward $\left(5^{\prime}-3^{\prime}\right)$ & Primer Reverse $\left(5^{\prime}-3^{\prime}\right)$ & Probe ( $5^{\prime}$ FAM- $3^{\prime}$ TAMRA) \\
\hline COL2A1 & $\begin{array}{c}5^{\prime} \text {-GGC AAT AGC AGG TTC } \\
\text { ACG TAC A-3 }{ }^{\prime}\end{array}$ & $\begin{array}{c}\text { 5'-GAT AAC AGT CTT GCC CCA } \\
\text { CTT ACC-3' }\end{array}$ & $\begin{array}{c}5^{\prime} \text {-CCT GAA GGA TGG CTG } \\
\text { CAC GAA ACA TAC-3' }\end{array}$ \\
\hline COL10A1 & $\begin{array}{c}5^{\prime} \text {-ACG CTG AAC GAT ACC } \\
\text { AAA TG-3 } 3^{\prime}\end{array}$ & $\begin{array}{c}5^{\prime} \text {-TGC TAT ACC TTT ACT CTT } \\
\text { TAT GGT GTA-3 }{ }^{\prime}\end{array}$ & $\begin{array}{c}\text { 5'-ACT ACC CAA CAC CAA } \\
\text { GAC ACA GTT CTT CAT TCC-3' }\end{array}$ \\
\hline ACAN & $\begin{array}{c}\text { 5'-AGT CCT CAA GCC TCC TGT } \\
\text { ACT CA-3' }\end{array}$ & $\begin{array}{c}\text { 5'-CGG GAA GTG GCG GTA } \\
\text { ACA-3' }\end{array}$ & $\begin{array}{l}5^{\prime} \text {-CCG GAA TGG AAA CGT } \\
\text { GAA TCA GAA TCA ACT-3 }{ }^{\prime}\end{array}$ \\
\hline RUNX2 & $\begin{array}{c}\text { 5'-AGC AAG GTT CAA CGA } \\
\text { TCT GAG AT-3' }\end{array}$ & $\begin{array}{c}\text { 5'-TTT GTG AAG ACG GTT ATG } \\
\text { GTC AA-3' }\end{array}$ & $\begin{array}{c}5^{\prime} \text {-TGA AAC TCT TGC CTC GTC } \\
\text { CAC TCC G-3' }\end{array}$ \\
\hline OC & 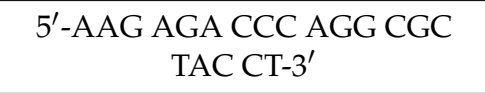 & $\begin{array}{c}5^{\prime} \text {-AAC TCG TCA CAG TCC } \\
\text { GGA TTG-3 } 3^{\prime}\end{array}$ & 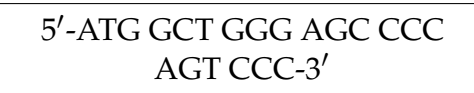 \\
\hline VEGF & $\begin{array}{c}5^{\prime} \text {-GCC CAC TGA GGA GTC } \\
\text { CAA CA-3 }\end{array}$ & $\begin{array}{c}5^{\prime} \text {-TCCTATGTG CTG GCC TTG } \\
\text { GT- } 3^{\prime}\end{array}$ & $\begin{array}{c}5^{\prime} \text {-CAC CAT GCA GAT TAT GCG } \\
\text { GAT CAA ACC T-3' }\end{array}$ \\
\hline RPLP0 & $\begin{array}{c}5^{\prime} \text {-TGG GCA AGA ACA CCA } \\
\text { TGA TG-3' }\end{array}$ & $\begin{array}{c}5^{\prime} \text {-CGG ATA TGA GGC AGC } \\
\text { AGT TTC- } 3^{\prime}\end{array}$ & $\begin{array}{c}5^{\prime} \text {-AGG GCA CCT GGA AAA } \\
\text { CAA CCC AGC-3' }\end{array}$ \\
\hline
\end{tabular}

RPLP0, ribosomal protein large P0 housekeeping gene; COL2A1, collagen type 2; COL10A1, collagen type 10; ACAN, aggrecan; RUNX2, runt-related transcription factor 2; OC, osteocalcin; VEGF, Vascular Endothelial Growth Factor.

\subsection{Histology and Immunohistochemistry}

After 14 days of culture, 70\% methanol-fixed constructs were frozen in OCT cryocompound Jung $\mathrm{GmbH}$, Nussloch, Germany) before being sectioned (10 $\mu \mathrm{m}$ thick) on a cryotome (Carl Zeiss AG, Oberkochen, Germany).

\subsection{Safranin O Staining}

Safranin O staining was performed to detect proteoglycan rich areas. Sectioned samples were incubated for 12 min in Weigert's Haematoxylin (Merck, Whitehouse Station, NJ, USA). The slides were then placed in lukewarm tap water for $10 \mathrm{~min}$, then briefly washed in distilled water and placed in $0.02 \%(v / v)$ Fast Green (Fluka, St. Louis, MO, USA) in $0.01 \%(v / v)$ acetic acid in deionized water for $5 \mathrm{~min}$. Fast green staining was followed by $30 \mathrm{~s}$ in $1 \%(v / v)$ acetic acid and then $5 \mathrm{~min}$ in $0.1 \%(w / v)$ Safranin O solution (ChromaGesellschaft Schmid GmbH \& Co, Münster, Germany). The slides were then dehydrated in $96 \%$ ethanol $2 \times 1 \mathrm{~min}$ and then 100\% ethanol twice ( 2 min each). Slides were then placed in $100 \%$ xylene for $2 \times 2$ min before being mounted using Eukitt mounting medium.

\subsection{Von Kossa Staining}

Sectioned samples were stained with Von Kossa for $30 \mathrm{~min}$ in 5\% (v/v) Silver Nitrate (Sigma Aldrich, Sigma-Aldrich, Buchs, Switzerland) with parallel exposure to strong light. The slides were then rinsed with deionized water and placed in 5\% $(v / v)$ Sodium Thiosulfate (Sigma Aldrich, Sigma-Aldrich, Buchs, Switzerland) for $10 \mathrm{~min}$. The sections were washed again with deionized water and counterstained for 10 min with $0.1 \%(v / v)$ Nuclear fast red (Fluka, St. Louis, MA, USA). The slides were then dehydrated in 70\% ethanol for $10 \mathrm{~s}, 96 \%$ ethanol for $1 \mathrm{~min}$ and then 100\% ethanol twice ( 2 min each). Slides were placed in 100\% xylene for $2 \times 2$ min before being mounted using Eukitt mounting medium.

\subsection{Immunostaining Collagen Type I and II}

The presence of collagen types I and II was determined using the following primary antibodies: COL-1 (C2456; Sigma-Aldrich) and CIICI (Developmental Studies Hybridoma Bank, University of Iowa, Iowa City, IA, USA). 
Sections were brought to room temperature and washed in distilled water for $10 \mathrm{~min}$ before native peroxidase activity was blocked with $0.3 \% \mathrm{H}_{2} \mathrm{O}_{2}$ (Fluka) in methanol (Brenntag) for $30 \mathrm{~min}$. Sections were then air-dried and washed twice for $5 \mathrm{~min}$ in $0.1 \%$ Tween20 PBS.

Sections were incubated in $0.05-0.5$ units / $\mathrm{mL}$ hyaluronidase (Sigma-Aldrich) in $0.1 \%$ Tween $20 \mathrm{PBS}$ at $37^{\circ} \mathrm{C}$ for $30 \mathrm{~min}$ before being washed three times for $5 \mathrm{~min}$ in $0.1 \%$ Tween-20 PBS. Sections were then blocked with horse serum diluted 1:20 in 0.1\% Tween-20 PBS for $1 \mathrm{~h}$ at room temperature. Following the blocking step, the serum was removed without washing and immediately replaced with the primary antibody for an incubation time of $30 \mathrm{~min}$ at room temperature.

The following dilutions with $0.1 \%$ Tween-20 were used for the antibodies: COL1 1:2000 and CIICI 1:6. Negative controls were incubated with $0.1 \%$ Tween20 PBS. Slides were then washed three times for 5 min with $0.1 \%$ Tween-20 PBS, before being incubated with the biotinylated anti-mouse IgG secondary antibody (Vector Laboratories, Burlingame, CA, USA) diluted 1:200 in 0.1\% Tween-20 PBS. Following this incubation, sections were washed again in $0.1 \%$ Tween-20 and then incubated with ABC solution (Vector Laboratories) for $30 \mathrm{~min}$ at room temperature, washed again, and then incubated with ImmPACT DAB (Vector Laboratories, Burlingame) for $4 \mathrm{~min}$ before being placed into distilled water. Samples were then counterstained with Mayer's haematoxylin (Sigma-Aldrich) for $20 \mathrm{~s}$ and blued in tap water for $5 \mathrm{~min}$. Samples were dehydrated in 50\%,70\%, 96\%, 100\%, 100\% ethanol before being cleared in xylene and mounted with Eukitt (Sigma-Aldrich).

\subsection{Statistical Analysis}

The data were produced from four individual experiments, each carried out with hMSCs from a different donor. All experiments were performed in triplicate and quadruplicate for each group at different timepoints in order to reduce methodological variability. Each measurement was performed in duplicate. Analyses were conducted between the appropriate control group and treatment groups, as well as between different treatment groups. The Shapiro-Wilk normality test was used to determine if data sets exhibited a normal distribution before statistical analysis. Where data were normally distributed, oneway ANOVA with Tukey's post hoc testing was applied. For data sets that did not show a normal distribution, the Friedman test with the uncorrected Dunn's test was applied.

A significance level of $p<0.05$ was applied and data are presented as Mean and Standard Deviation. Analyses were carried out using the GraphPadPrism 8.1 software (GraphPad Software Inc., La Jolla, CA, USA)

\section{Results}

Due to donor variation, studying osteogenesis and chondrogenesis in parallel, with the same population of cells, can aid in the understanding of specific factors supplemented in the media and their interaction with oxygen tension. With this in mind, we analyzed the gene expression of the same cell population after 2 weeks of different stimuli.

\subsection{Gene Expression Analysis}

A panel of genes associated with chondrogenic differentiation (Collagen type II, Aggrecan, SOX9), hypertrophy (Collagen type $X$ and alkaline phosphatase (ALP)), and osteogenic differentiation (RUNX2, Osteocalcin (OC)) were investigated on day 14 (Figure 2). The four donors which were investigated all displayed the same pattern of expression to a varying degree of magnitude.

Relative quantification of target mRNA was performed according to the comparative $\mathrm{Ct}$ method. COL2A1 is relative to BMP2 free osteogenic condition as it was not expressed by all donors on Day 0. Values represent the mean and standard deviation of four independent hBMSC donors in experimental triplicate. Statistical significance was defined as ${ }^{*} p<0.05$ and ${ }^{* *} p<0.01$. 

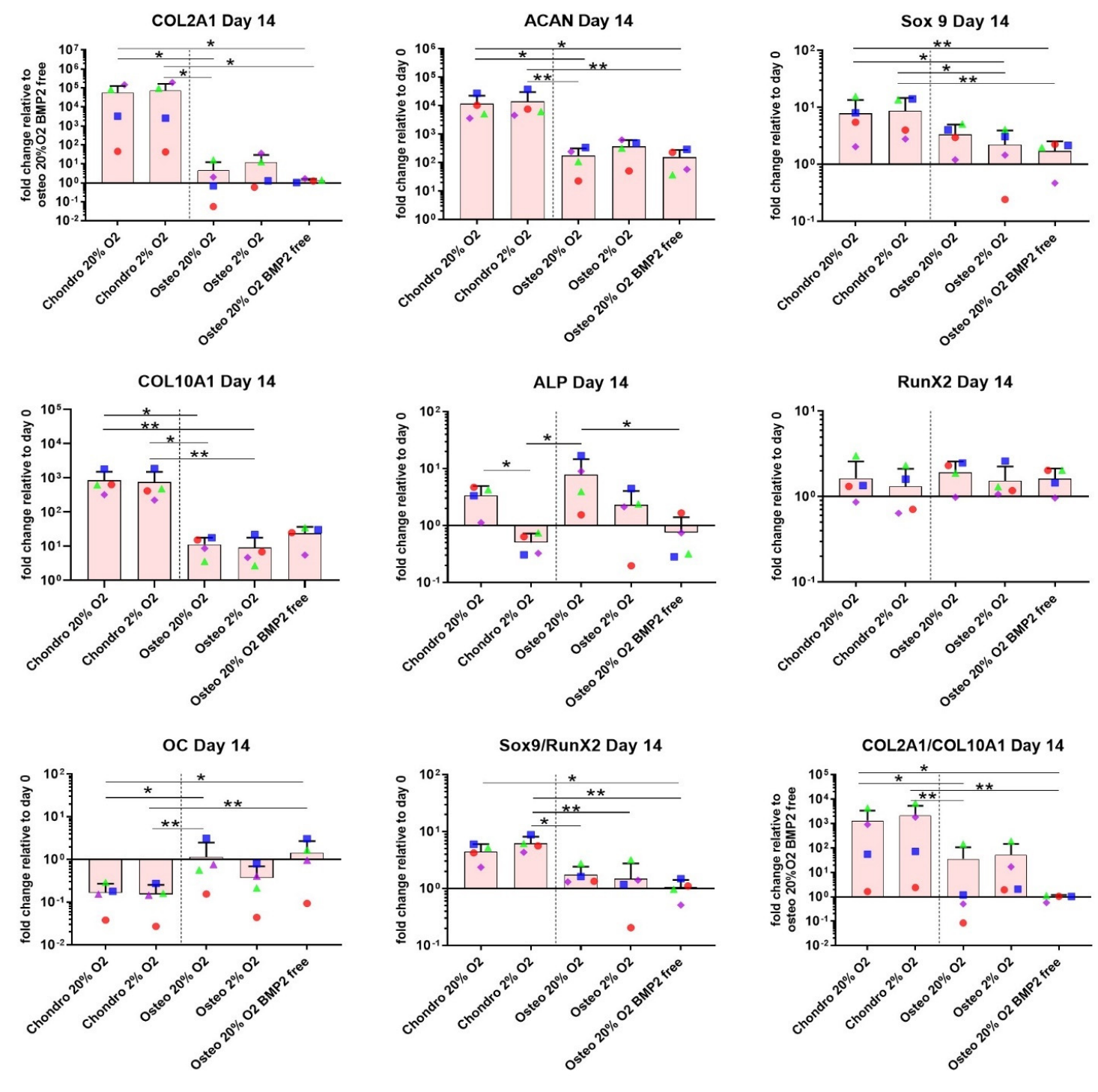

-Donor 1

Donor 2

Donor 3

$\bullet$ Donor 4

Figure 2. Gene expression measured at day 14 by real-time polymerase chain reaction (qPCR) of chondrogenic and osteogenic scaffolds. A significant upregulation of the chondrogenic markers Collagen type II, Aggrecan and SOX9, and the hypertrophic marker Collagen type $X$, was observed in the chondrogenically differentiated constructs compared with osteogenic samples. The Sox9/Runx2 and Col2A1/Coll10A1 ratios were also greater in chondrogenic samples. Furthermore, ALP gene expression was consistently downregulated in chondrogenically differentiated constructs under $2 \%$ oxygen tension. An upregulation of ALP was observed in the osteogenically differentiated constructs, with the exception of BMP2 combined with $20 \% \mathrm{O}_{2}$. Statistical significance was defined as ${ }^{*} p<0.05$ and ${ }^{* *} p<0.01$.

Collagen type II and aggrecan show a very similar gene expression profile and a significant upregulation of these two genes was observed in the chondrogenic groups, particularly between (1) chondro $20 \% \mathrm{O}_{2}$ and osteo $20 \% \mathrm{O}_{2}\left({ }^{*} p<0.05\right.$ ), and (2) chondro $2 \%$ $\mathrm{O}_{2}$ and osteo $20 \% \mathrm{O}_{2}\left({ }^{*} p<0.05\right.$ or $\left.{ }^{* *} p<0.01\right)$, independently of the presence or absence of BMP2 (Figure 2). SOX9 showed a similar profile to collagen type II and aggrecan, with the exception that significant differences in the osteo-chondro group comparison were detected between the chondro groups and Osteo $2 \% \mathrm{O}_{2}\left({ }^{*} p<0.05\right)$. Osteogenic differentiation led to lower SOX9 expression than chondrogenic groups independent of oxygen tension. Osteo $20 \% \mathrm{O}_{2}$ BMP2 free showed a significantly lower SOX9 expression than the chondrogenic groups $(* * p<0.01)$.

The hypertrophic marker collagen type $X$ showed a significant upregulation in the chondrogenically differentiated groups compared with the osteogenically differentiated 
groups, and differences were independent of the oxygen tension applied $\left({ }^{*} p<0.05\right.$ and ** $p<0.01$ ). However, the absence of BMP2 from the osteogenic media led to a loss of significance in the osteo-chondro comparison due to a slight increase in collagen $X$ expression in the osteo $20 \% \mathrm{O}_{2} \mathrm{BMP} 2$ free group. ALP expression was downregulated under $2 \% \mathrm{O}_{2}$ compared to $20 \% \mathrm{O}_{2}$ for both chondrogenesis and osteogenesis in the presence of BMP2, although this only reached significance for chondrogenesis $\left({ }^{*} p<0.05\right)$.

In three out of four donors, RUNX2 was downregulated during chondrogenesis under low $\mathrm{O}_{2}$, although no statistically significant differences were detected as donor 2 actually had an increase in RUNX2 expression. The gene expression ratios SOX9/and Collagen type II/Collagen type X were significantly upregulated RUNX2 $\left({ }^{*} p<0.05\right.$ or $\left.{ }^{* *} p<0.01\right)$ in the chondrogenic groups. The differences between chondro and osteo groups were more marked when chondro groups were differentiated under lower $\mathrm{O}_{2}(* * p<0.01)$ than $20 \%$ $\mathrm{O}_{2}\left({ }^{*} p<0.05\right)$. These last two results indicate that low $\mathrm{O}_{2}$ is beneficial, leading to more reproducible increases in the SOX9/RUNX2 and Collagen type II/Collagen type X ratios.

The data shows that while chondrogenic differentiation behaved generally as expected, osteogenic medium in the absence of BMP2 combined with 3D culture conditions showed an expression pattern that may be more indicative of endochondral ossification, as indicated by the higher SOX9/RUNX2 and Collagen type II/Collagen type X ratios. Osteocalcin was significantly upregulated in the osteogenic groups under $20 \% \mathrm{O}_{2}$ independently of the addition of BMP2 when compared with the chondrogenic groups $\left({ }^{*} p<0.05\right.$ and $\left.{ }^{* *} p<0.01\right)$. Conversely, the $2 \% \mathrm{O}_{2}$ osteogenic group tended to suppress OC gene expression (Figure 2). VEGF expression was unaffected by oxygen tension but was significantly upregulated under osteogenic conditions (Figure 3). HIF1 $\alpha$ was largely unaffected by all conditions investigated. (Figure 3).
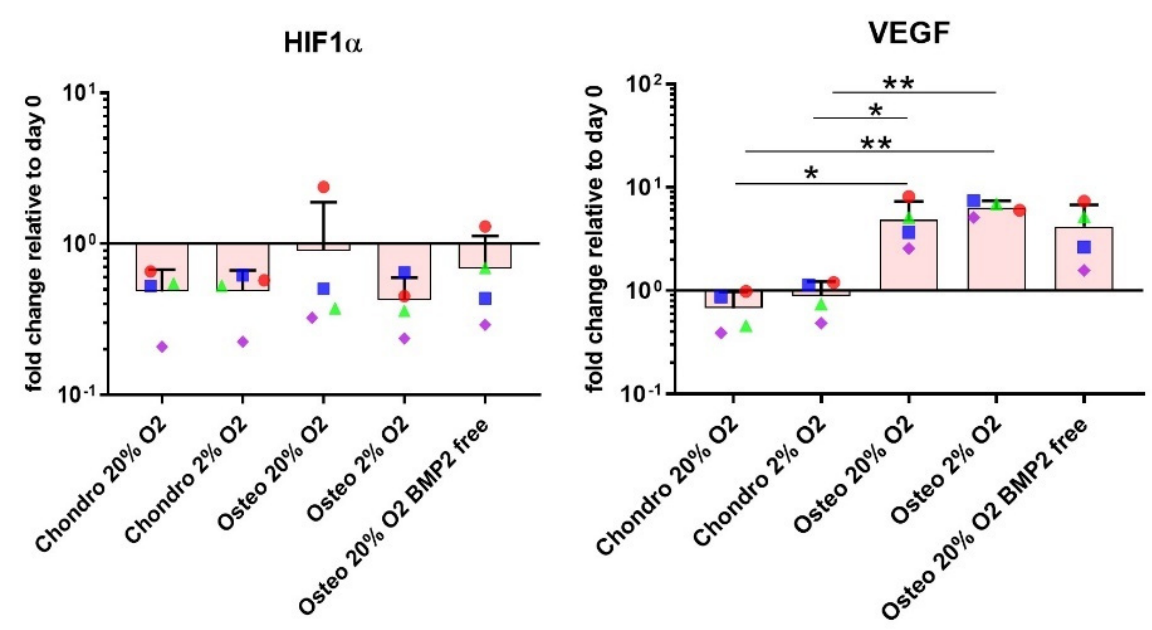

Figure 3. Gene expression measured at day 14 of differentiation by real-time polymerase chain reaction (qPCR). VEGF gene expression was significantly upregulated in the osteogenic groups supplemented with BMP2. Relative quantification of target mRNA was performed according to the comparative $\mathrm{Ct}$ method. Values represent the mean and standard deviation of four independent hBMSC donors in experimental triplicate. Statistical significance was defined as ${ }^{*} p<0.05$ and ${ }^{* *} p<0.01$.

\subsection{Sulphated Glycosaminoglycan and DNA Quantification}

As expected, due to the different seeding concentrations ( 3.5 versus $2 \times 10^{6}$ cells/scaffold), after 2 weeks in culture, the DNA content of chondro $20 \% \mathrm{O}_{2}$ was significantly higher compared to all osteogenic groups (Figure 4A). Although the DNA content of the chondro $20 \% \mathrm{O}_{2}$ group is similar to $2 \% \mathrm{O}_{2}$, the latter did not reach significance due to the higher standard deviation. Absence of BMP2 in the osteogenic culture media slightly increased the DNA content of the osteo $20 \% \mathrm{O}_{2}$ group but this increase is not statistically different to the other osteogenic groups. 
A

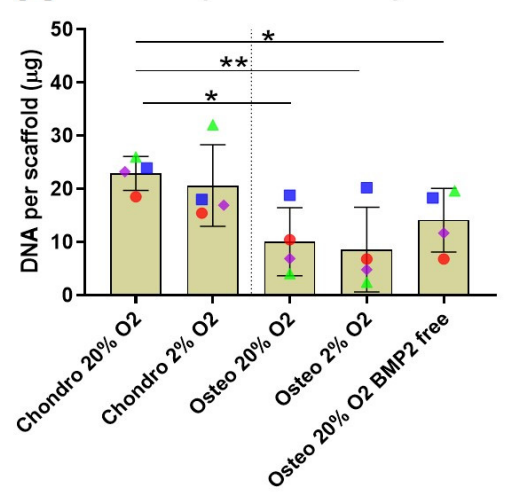

C GAG per scaffold/DNA Day 14
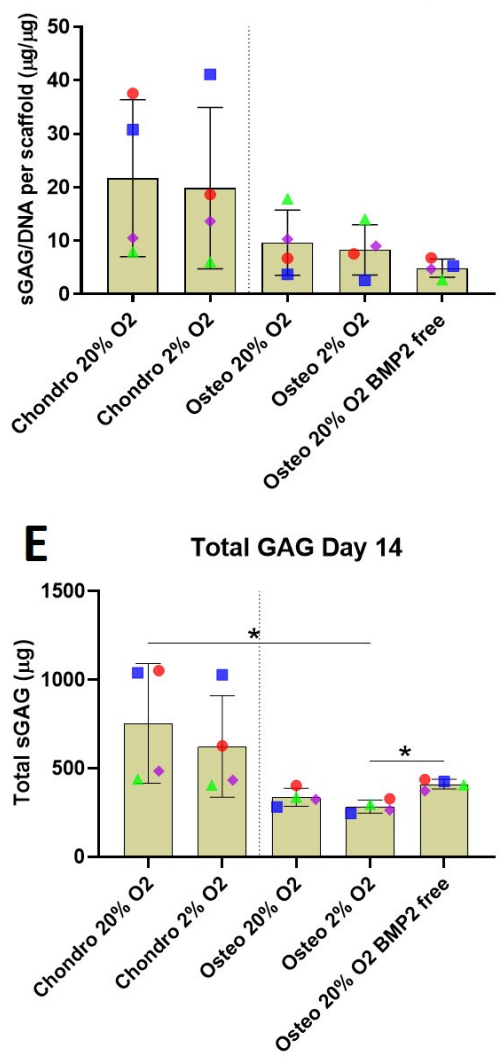

- Donor 1

- Donor 2
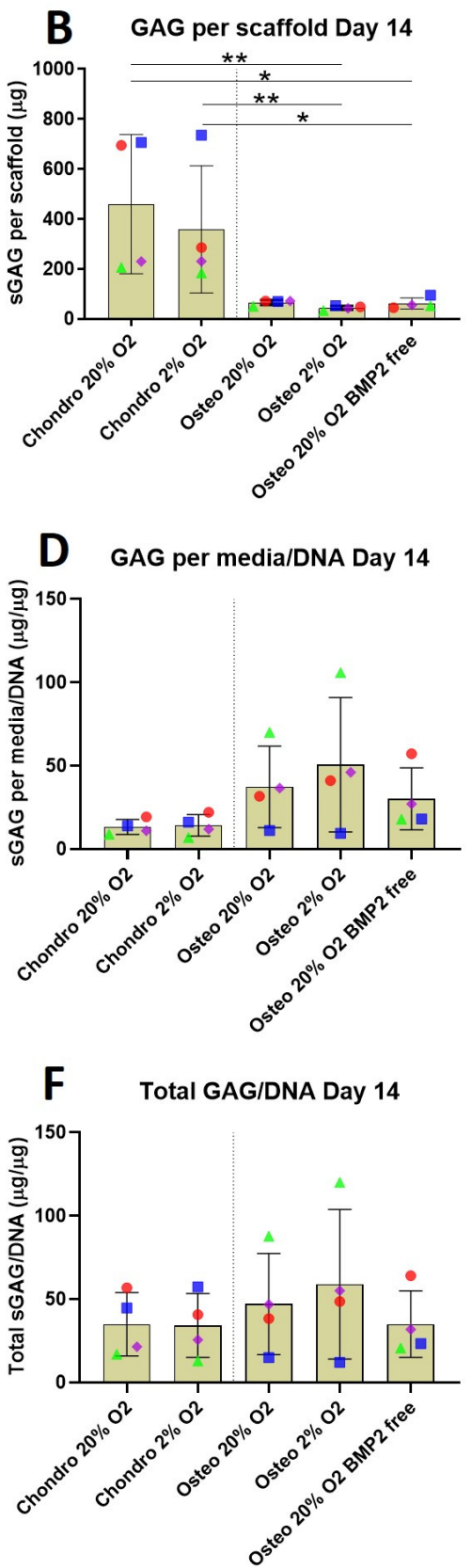

$\triangle$ Donor 3

Donor 4

Figure 4. Biochemical analysis of chondrogenically and osteogenically differentiated constructs after 2 weeks in culture shows a significantly higher sulphated glycosaminoglycan deposition in chondrogenically differentiated constructs independent of oxygen tension. (A) Bisbenzimide Höchst 33528 dye was used to quantify the DNA in proteinase K digests of scaffolds. (B-F) Dimethylmethylene blue (DMMB) at $\mathrm{pH} 3$ was used to determine the sulphated glycosaminoglycan (GAG) produced by mesenchymal stem cells (MSCs): (B) sulphated glycosaminoglycan produced by MSCs and deposited inside the scaffold: (C) GAG/DNA per scaffold: (D) culture media GAG normalized to DNA: (E) cumulative GAG deposited into the scaffold and released in culture media; (F) Total GAG/DNA. Values represent the mean \pm SD of four independent hBMSC donors in experimental triplicate or quadruplicate. Statistical significance was defined as ${ }^{*} p<0.05$, and ${ }^{* *} p<0.01$.

After 14 days of differentiation, chondrogenically differentiated constructs consistently accumulated more sGAG inside the scaffolds compared with osteogenically differentiated constructs (Figure 4B). No oxygen tension or BMP2-related differences were observed. 
The scaffold GAG/DNA ratio (Figure 4C) was very similar in the overall profile to the sGAG per scaffold with a higher value for the chondrogenic groups compared with the osteogenic groups. Unexpectedly, the media GAG/DNA ratio (Figure 4D) showed an opposite trend, with the osteogenic groups showing a higher GAG content compared to the chondrogenic groups.

The amount of total GAG produced by the chondrogenic groups showed a higher average compared with the osteogenic groups (Figure 4E). However significant differences were identified only between the chondro $20 \% \mathrm{O}_{2}$ and osteo $2 \% \mathrm{O}_{2}$. The GAG level of the latter group was also significantly lower compared to the osteo $20 \% \mathrm{O}_{2} \mathrm{BMP} 2$ free group. Total GAG/DNA (Figure 4F) is very similar among the various groups with a slightly higher average value for the osteogenic groups supplemented with BMP2; the main difference was the location of the GAG, with chondrogenic retaining a greater proportion in the scaffold, and osteogenic retaining a greater proportion in the media.

A more detailed analysis of GAG release into the media over time showed the osteogenically differentiated groups released significantly more GAG into the culture media compared to the chondrogenically differentiated constructs during the first 7 days of differentiation (Figure 5). The difference is attenuated over time, although the osteo $20 \% \mathrm{O}_{2}$ group lacking BMP2 continued to release a significantly higher amount of GAG into the media supernatant in the second week of differentiation. Thus, the chondrogenic media supplemented with TGF $\beta 1$ significantly facilitated differentiation, while the absence of BMP2 in the osteogenic culture media increased GAG release from day 4 onward.
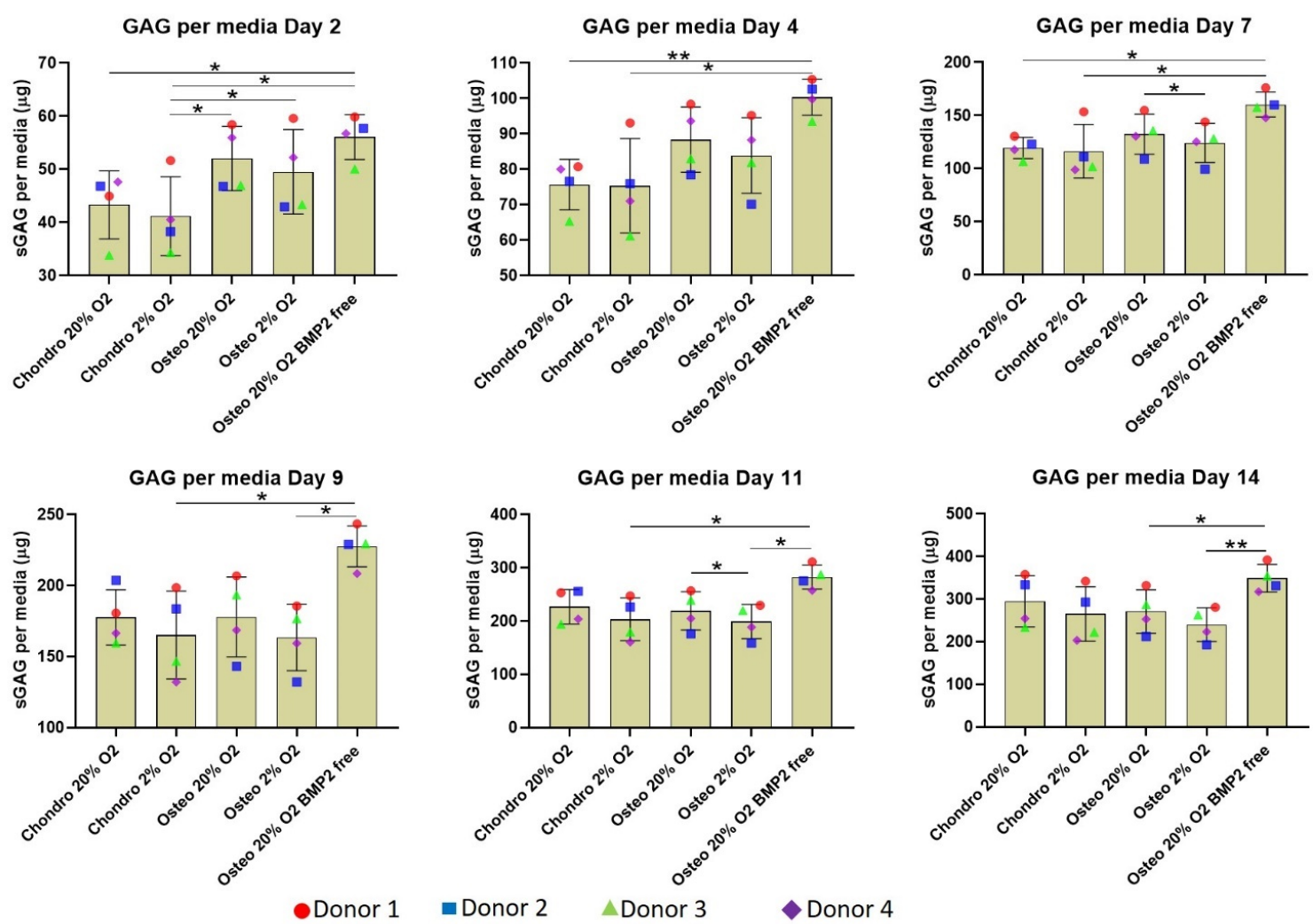

Figure 5. GAG produced and released into culture media from scaffolds over 2 weeks in culture. In the first 7 days, the osteogenically differentiated groups released significantly more GAG into the culture media compared with the chondrogenically differentiated constructs. The absence of BMP2 in the osteogenic media kept the media GAG higher until day 14. sGAG content in culture medium was determined spectrophotometrically following reaction with 1.9-dimethylmethylene blue (DMMB) $\mathrm{pH}$ 3. Values represent the mean \pm SD of three independent hBMSC donors in experimental quadruplicate or quintuplicate. Statistical significance was defined as ${ }^{*} p<0.05$ and ${ }^{* *} p<0.01$. 


\subsection{Histology \& Immunohistochemistry}

After 14 days of chondrogenic or osteogenic differentiation, samples were stained with Safranin O and counterstained with Fast green in order to detect sulphated GAGs deposition (Figures 6-9). Positive Safranin O staining was present along the upper and lateral surface of the constructs differentiated with chondrogenic media, with the exception of Donor2 hypoxia tended towards on increased staining under low oxygen conditions. No Safranin O staining was observed in the osteogenically differentiated constructs under any condition.

Von Kossa staining highlighted a mineral deposition in the osteogenically differentiated constructs only when the media was supplemented with BMP2. None or very low mineral deposition was observed in the absence of BMP2 demonstrating, also in our system, that BMP2 enhances the osteogenic differentiation capacity of mesenchymal stromal cells derived from human bone marrow [38]. No relevant differences in mineral deposition were observed at the different oxygen tensions.

Collagen type I deposition was evident in chondrogenically differentiated groups, with reduced the collagen type I deposition under low oxygen. Osteogenically differentiated constructs showed an overall notable reduction in the collagen type I deposition compared with chondrogenically differentiated groups. The BMP2 supplemented osteogenic media did not affect the Collagen type I deposition. However, for donor 3, the absence of BMP2, led to an increased collagen type I deposition. Immunohistochemistry showed that collagen type II was found only in chondrogenically differentiated groups, similarly to safranin O staining, collagen II staining was increased under low oxygen, with the exception of Donor2.

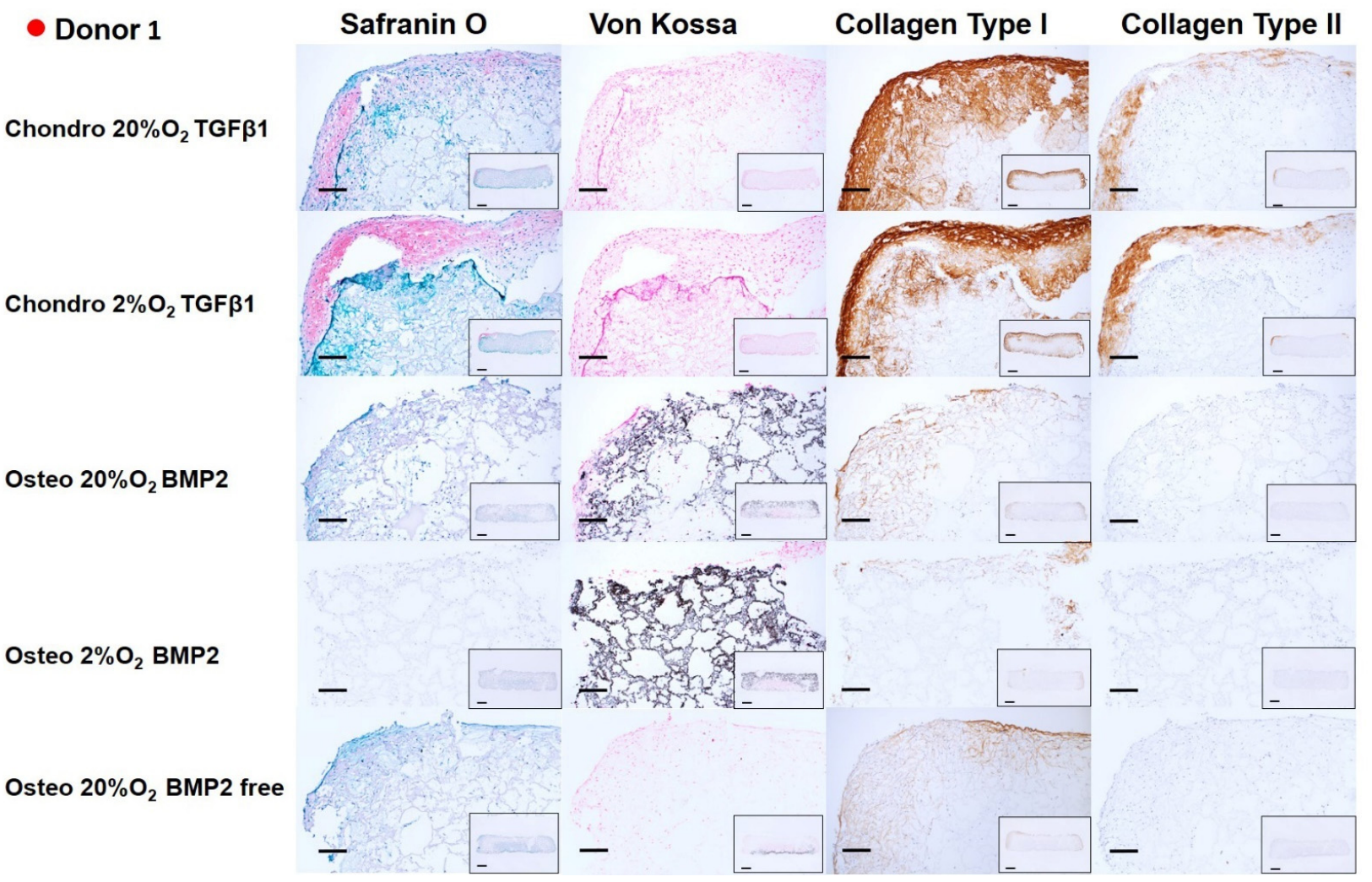

Figure 6. Chondrogenic and osteogenic hBMSC-constructs after 2 weeks of culture. Images showing a higher magnification of donor 1. Scale bar: $200 \mu \mathrm{m}$. Inset: Images showing the full section of the constructs 1 . Scale bar: $1 \mathrm{~mm}$. Scaffolds were stained with safranin O/Fast Green, Von Kossa and immunohistochemically labelled for collagen type I and collagen type II. Chondrogenically differentiated groups showed higher Safranin O, Collagen Type I and Collagen type II deposition. The osteogenically differentiated groups with BMP2 are positive for Von Kossa staining. 


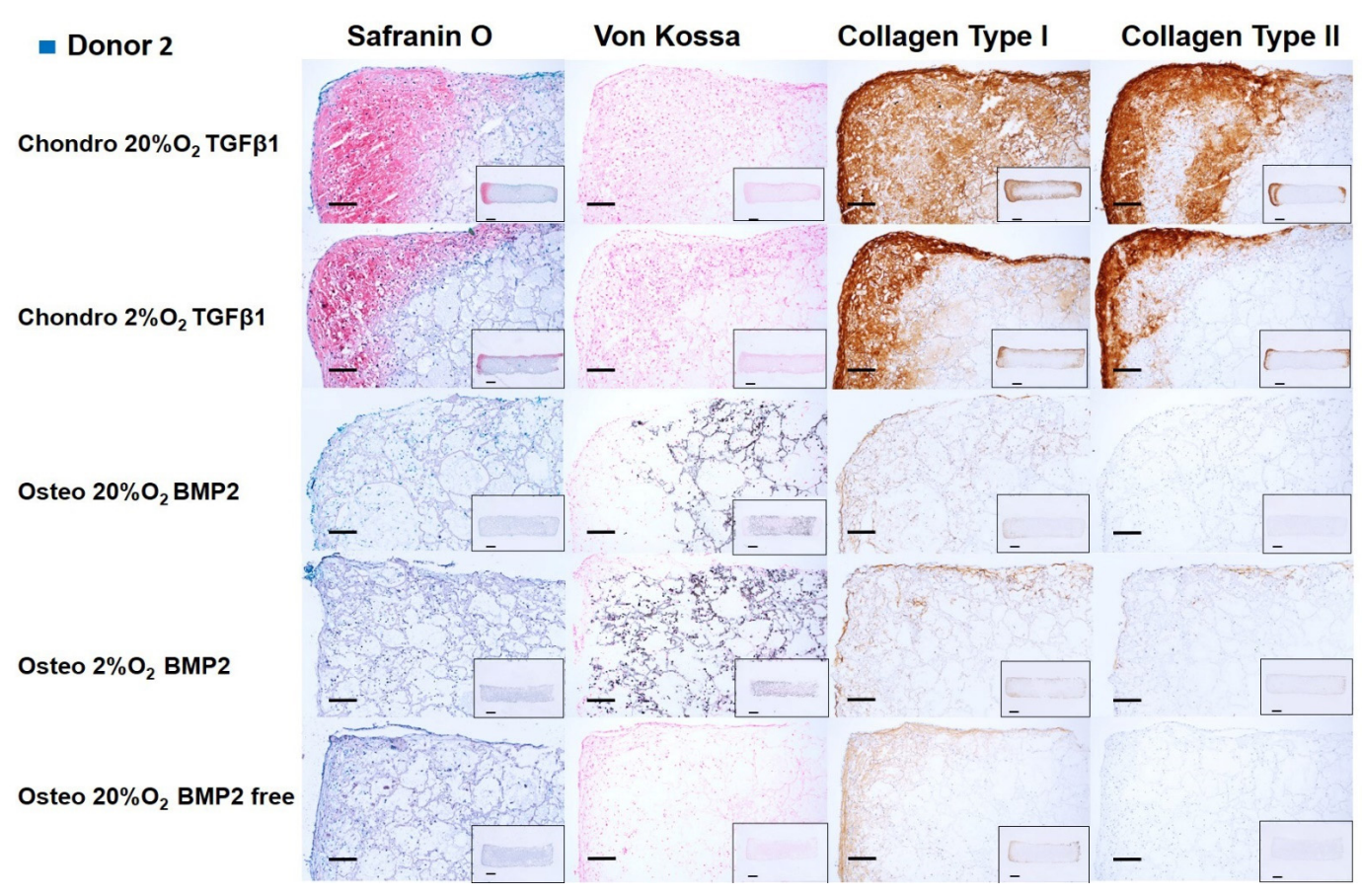

Figure 7. Chondrogenic and osteogenic hBMSC-constructs after 2 weeks of culture. Images showing a higher magnification of donor 2. Scale bar: $200 \mu \mathrm{m}$. Inset: Images showing the full section of the constructs 1 . Scale bar: $1 \mathrm{~mm}$. Scaffolds were stained with safranin O/Fast Green, Von Kossa and immunohistochemically labelled for collagen type I and collagen type II. Chondrogenically differentiated groups showed higher Safranin O, Collagen Type I and Collagen type II deposition. The osteogenically differentiated groups with BMP2 are positive for Von Kossa staining.

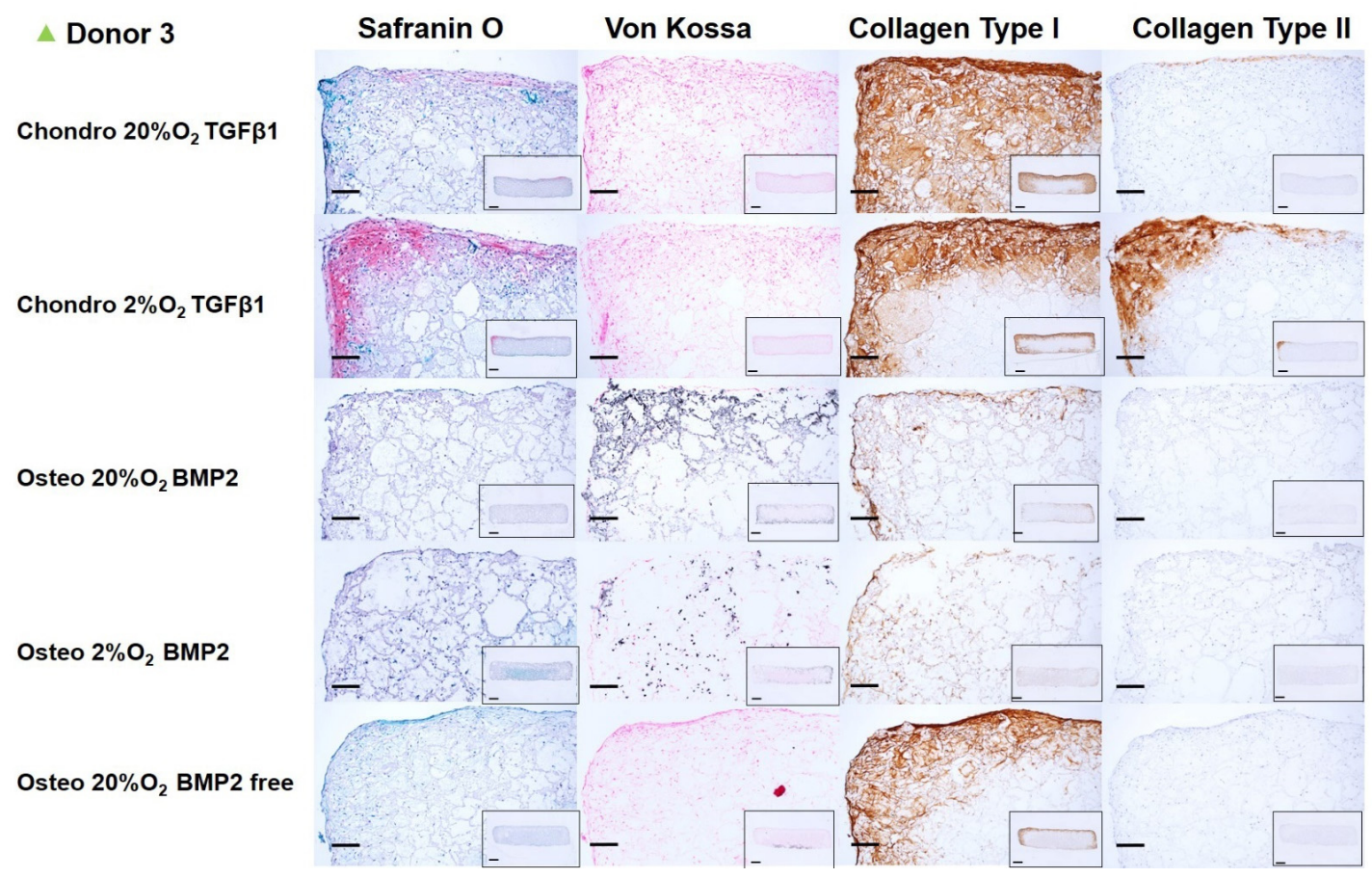

Figure 8. Chondrogenic and osteogenic hBMSC-constructs after 2 weeks of culture. Images showing a higher magnification of donor 3. Scale bar: $200 \mu \mathrm{m}$. Inset: Images showing the full section of the constructs 1 . Scale bar: $1 \mathrm{~mm}$. Scaffolds were stained with safranin O/Fast Green, Von Kossa and immunohistochemically labelled for collagen type I and collagen type II. Chondrogenically differentiated groups showed higher Safranin O, Collagen Type I and Collagen type II deposition. The osteogenically differentiated groups with BMP2 are positive for Von Kossa staining. 


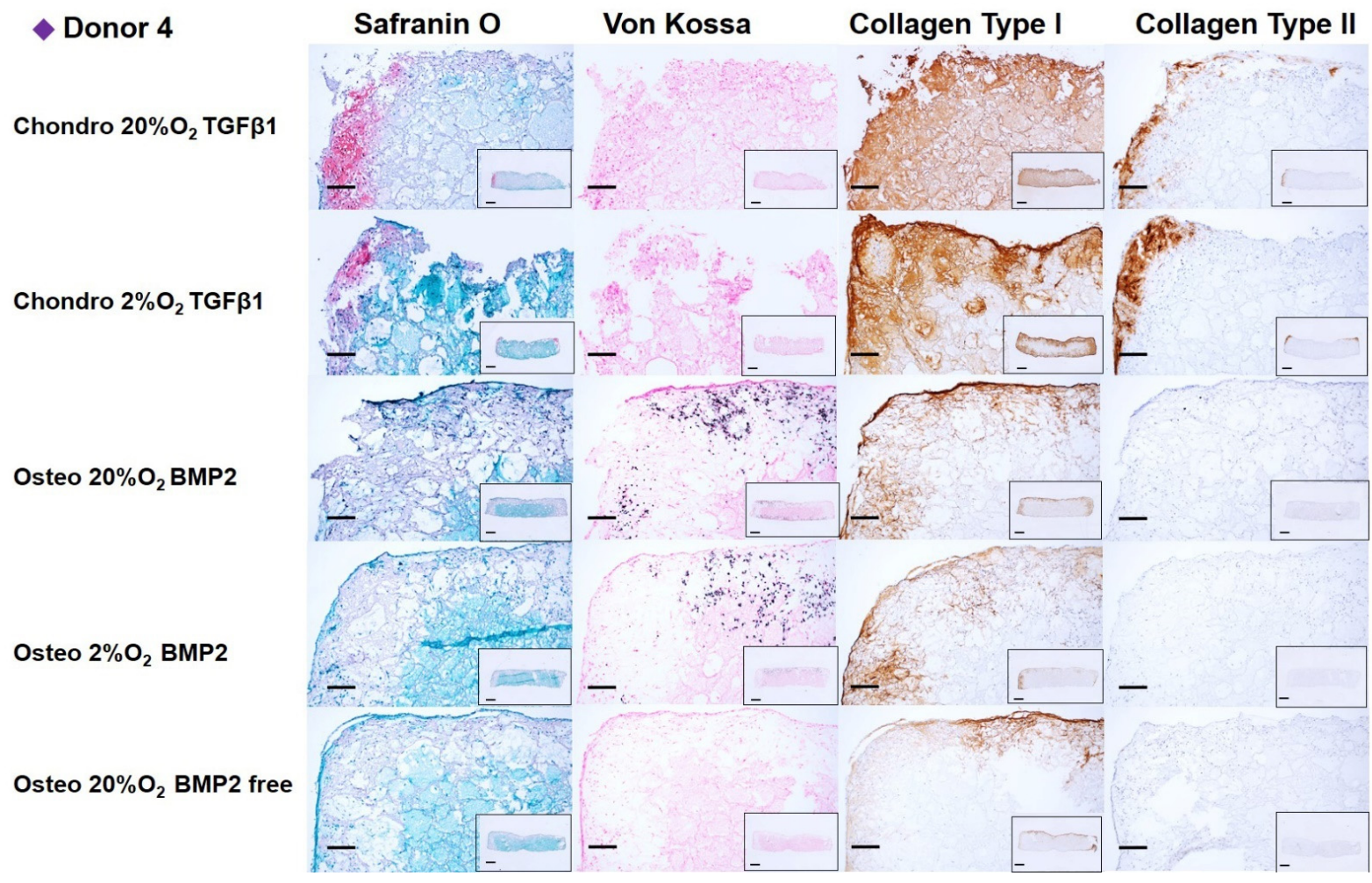

Figure 9. Chondrogenic and osteogenic hBMSC-constructs after 2 weeks of culture. Images showing a higher magnification of donor 4. Scale bar: $200 \mu \mathrm{m}$. Inset: Images showing the full section of the constructs 1 . Scale bar: $1 \mathrm{~mm}$. Scaffolds were stained with safranin O/Fast Green, Von Kossa and immunohistochemically labelled for collagen type I and collagen type II. Chondrogenically differentiated groups showed higher Safranin O, Collagen Type I and Collagen type II deposition. The osteogenically differentiated groups with BMP2 are positive for Von Kossa staining.

\section{Discussion}

MSCs have been extensively explored as a source of cells, generating major clinical interest, and are easy to isolate without creating any morbidity site. They represent an emerging advanced-therapy medicinal product (ATMP) treatment $[39,40]$. Numerous studies have investigated the role of growth factors and oxygen tension on the differentiation of hMSCs. In this study, we provide a unique comparison of multiple conditions on multiple human donors. In the present work, autologous MSCs from four different human bone marrow donors were isolated and expanded in 2D culture following identical protocols. This approach provided a uniformly treated batch of MSCs that offered an initial common and unequivocal baseline from which to start the chondrogenic and osteogenic differentiation procedures. Therefore, after 14 days of 3D culture, we can directly compare the behavior and response of the same cell population towards the two differentiation protocols in separate constructs. When considering the data, it is noteworthy that osteogenic media is routinely used in 2D conditions such as monolayer. Differences observed in our system during osteogenesis may also be due to 3D-encapsulated cells being subjected to media typically used under 2D conditions. Thus, the same media may have different outcomes depending on the culture system used, and this should be further investigated in future studies.

As expected, our findings show that culture media and oxygen tension influences hMSC differentiation. Particularly at day 14, we consistently observed for the chondrogenically differentiated groups: 
- A notable upregulation of chondrogenic gene expression markers and SOX9/RUNX2 and COL2A1/COL10A1 ratios.

- A consistent and significant downregulation of hypertrophic marker alkaline phosphatase (ALP) gene expression under low oxygen tension.

- A notably higher sGAG production and deposition within the constructs.

- Positive staining for safranin O, Collagen type I and II.

- Increased staining for safranin $\mathrm{O}$ and Collagen type II under $2 \% \mathrm{O}_{2}$ in 3 from 4 donors.

- $\quad$ Slight reduction of the Collagen type I deposition under $2 \% \mathrm{O}_{2}$.

- For the osteogenically differentiated groups:

- An overall upregulation of osteogenic markers gene expression.

- A significant upregulation of ALP in BMP2 supplemented media under 20\% $\mathrm{O}_{2}$ tension.

- A slightly reduced upregulation of ALP and OC under $2 \% \mathrm{O}_{2}$ tension.

- A very low sGAG deposition within the constructs.

- A significant increase in media sGAG in the absence of BMP2 at day 14

- $2 \% \mathrm{O}_{2}$ reduced the ALP and OC gene expression.

- Positive Von Kossa staining only in the presence of BMP2, low collagen type I deposition and absence of collagen type II deposition in all groups.

\subsection{Low Oxygen Tension Induces A Significant Downregulation of Alp Gene Expression in Chondrogenic Media}

Several studies have shown that differences in oxygen tension can affect MSC differentiation with varying results $[28,41]$. High in vitro $\mathrm{O}_{2}$ tension negatively affects MSC chondrogenesis and results in the expression of the hypertrophic markers collagen Type $X$ and ALP, which upon in vivo implantation in nude mice results in ectopic bone formation [42]. The chondrogenic fate of young porcine MSCs can be metabolically programmed by low oxygen tension to acquire an articular chondrocyte-like phenotype via mechanisms that resemble natural development [28]. Yet, studies with human cells have shown considerably more variation [28,41]. Furthermore, the response to oxygen has been shown to be material dependent. Human MSCs demonstrated reduced expression of ALP and collagen $\mathrm{X}$ at $1 \% \mathrm{O}_{2}$ when encapsulated in low concentration Hyaluronan (HA) gels; yet, the opposite was true when the HA concentration was increased to 5\% [43], with the authors speculating that the differences were due to the ability of the gel to retain pericellular matrix. At $5 \% \mathrm{O}_{2}$, hBMSCs in alginate beads, which retain most of the de novo matrix, continued to show an increased expression of the chondrogenic marker SOX9, ACAN and Collagen type II and a decrease in the ALP and RUNX2, with donor dependent changes in Collagen type X [44].

Within our system, fibrin is not very efficient at retaining de novo matrix and our results were intermediate, with a consistent downregulation of ALP. The ALP data would be strengthened by additional protein data, but this was not performed. Of note, ALP has multiple functions, not all of which are bone related [45]. This opens the possibility that the observed changes are related to changes in metabolism, but more detailed analysis would be needed to investigate this aspect. In contrast with our ALP finding, we did not observe a downregulation of collagen type $\mathrm{X}$ expression under $2 \% \mathrm{O}_{2}$ chondrogenesis. Although several studies have shown a reduction in collagen type $\mathrm{X}$ expression under low oxygen $[46,47]$, other studies report a negligible effect or even an upregulation of collagen type $\mathrm{X}$ gene expression [48,49]. In this regard, our findings belong to the latter group of studies where a negligible effect has been observed. It would be interesting to confirm collagen type $X$ deposition at the protein level in our experiments, however, this was not possible due to the lack of a suitable antibody that does not cross-react with the fibrin glue used in our constructs.

Despite the samples being contained within a validated hypoxic chamber, there was a lack of a difference in VEGF and HIF1 $\alpha$ expression with low $\mathrm{O}_{2}$. The reasons for this are unclear, but it suggests a more robust $\mathrm{O}_{2}$ related response could be obtained. It has also been previously demonstrated that regulation of HIF1 $\alpha$ in hMSCs under low oxygen 
is largely dependent on the underlying chondrogenic potential of the cells [46]. The lack of response suggests that the ALP gene expression changes seen in both chondrogenic and osteogenic conditions are not HIF1 $\alpha$ driven. A further reason why the material used, and the implant size, may affect responses to oxygen tension could be due to the differing diffusion rates into the scaffold. Larger, or more dense scaffolds, with a high cell density may already be largely hypoxic due to diffusion limits and this may have played a role with our $8 \mathrm{~mm} \times 4 \mathrm{~mm}$ scaffolds containing more the 2 million cells.

Osteocalcin was not markedly expressed at day 14 , potentially because it is a later osteogenic marker. RUNX2 was not particularly affected by the differentiation process in either differentiation processes, although chondrogenic differentiation under low oxygen appeared to downregulate its expression for two donors. During osteogenesis, the downregulation of SOX9, rather than the upregulation of RUNX2, has been shown to be a more predictive marker of osteogenic potential when using human bone marrow derived MSCs. Under chondrogenic culture conditions the SOX9/RUNX2, an indicator of chondrogenic versus osteogenic differentiation, and COL2A1/COL10A1, an indicator of resting chondrogenesis versus endochondral ossification, ratios were significantly higher if compared with the osteogenic groups.

\subsection{Chondrogenic TGFß1-Supplemented Media Promotes sGAG Deposition while Osteogenic Media without BMP2 Induces SGAG Release in the Culture Supernatant}

Previous studies also reported an increased GAG and matrix production in chondrogenic cultures under low oxygen tension for pellet and 3D scaffold constructs using chondrocytes, articular cartilage progenitors and MSCs [43,50-52]. However, other studies did not identify significant increases in GAG production or reported a reduced matrix production under $1 \%$ to $5 \% \mathrm{O}_{2}$ in hMSCs in pellet or scaffold cultures [53,54]. The different oxygen densities used in the present work did not exert any noticeable effect on GAG deposition, which is in line with the latter studies mentioned above.

In this study, the level of sGAG deposition inside the 3D MSC-based constructs was significantly higher in the chondrogenic constructs, presumably due to TGF $\beta 1$ supplementation $[31,55,56]$. In addition, sGAG content was also quantified in the culture media. We observed a significantly increased sGAG release into the culture media for all osteogenically differentiated groups from day 2 . The release of sGAG was attenuated over time in BMP2 containing media. However, in the absence of BMP2, the high sGAG release was maintained until day 14 . We are not aware of any reports investigating GAG production during osteogenesis in vitro. As the GAG production during 3D osteogenesis does appear to be significant, we propose this marker to be adopted for future 3D osteogenesis studies. In vivo, GAG production is observed during endochondral ossification. The release into the medium observed here may provide an indication that indirect versus direct differentiation is occurring. Of note, donor 2 and donor 3 showed an opposite behavior depending on which medium they are exposed to, thus highlighting the inherent problems of donor variation, with methods to predict cell function being needed [57]. Alternatively, a higher number of donors with non-statistical based methods of analysis will be needed. By studying multiple conditions with the same starting cell population of cells, as undertaken here, the donor variation can be better assessed, leading to more clinically relevant results.

4.3. TGF $\beta 1$ - Supplemented Chondrogenic Media under $2 \% \mathrm{O}_{2}$ Tension Promotes Cartilage-Like Matrix Deposition and Reduces Collagen Type I, While BMP2-Supplemented Osteogenic Media Promotes Matrix Mineralization

Chondrogenic differentiation of hMSCs led to positive staining by Safranin O, especially at the borders of the constructs and in the areas where a higher cell density was seeded following the asymmetric seeding approach previously described [35]. In addition to the asymmetric seeding, the higher matrix deposition at the edges of the constructs may have been influenced by the facilitated oxygen and nutrient exchange at the upper and side of the constructs rather than in the middle, or at the bottom edge that was in contact with the multi-well plate surface. However, metabolically active cells were present in the center 
of the construct, as shown by the mineralized matrix found throughout the whole scaffold, especially for donors 1 and 2, under osteogenic conditions. In the chondrogenic groups, collagen II deposition was identified in the same areas of the constructs positively stained by Safranin O, and both increased under $2 \% \mathrm{O}_{2}$ in 3 from four donors. Similarly, to previous studies [46], the effect of low oxygen was dependent on the chondrogenic potential of the donor, with the most chondrogenic donor (Donor2) being the least responsive to low $\mathrm{O}_{2}$. Collagen type I deposition was detected in more extended regions of the scaffold's edges. The low oxygen density $\left(2 \% \mathrm{O}_{2}\right)$ reduced the collagen type I deposition compared to higher oxygen density $\left(20 \% \mathrm{O}_{2}\right)$. Indeed, collagen type I staining was present on all edges and penetrated the scaffold to a larger extent under $20 \% \mathrm{O}_{2}$. Although several studies suggest an increase in collagen type II gene expression or protein deposition under low oxygen condition, they also report a parallel increase in collagen type I. Other studies report a downregulation of matrix gene expression (SOX9, COL2A1, ACAN) with no effect on matrix formation $[53,58,59]$.

Following 14 days of MSC osteogenic differentiation, mineralized matrix was positively stained by Von Kossa and a notable reduction in collagen I deposition was observed in comparison with the chondrogenic groups. In addition, a more marked reduction in collagen I was present in the same areas of the constructs where a higher degree of mineralization occurred. This inverse correlation between collagen I deposition and degree of mineralization is consistent in all the donors investigated. As expected, most of the mineralization occurred when BMP2 was supplemented in the culture media.

Although the ideal oxygen concentration for MSC chondrogenic differentiation has been broadly accepted as low, conflicting outcomes exist for defining the ideal oxygen tension to achieve a proper MSCs osteogenic differentiation. Osteogenic differentiation in a culture media supplemented with $100 \mathrm{ng} / \mathrm{mL}$ BMP2 with a very similar composition to that used in this study, appeared to be inhibited under $1 \% \mathrm{O}_{2}$ while the increase to $3 \% \mathrm{O}_{2}$ restored osteogenesis [60]. In contrast to previous studies, Wagegg et al., showed hypoxia as a promoter of hBMSC osteogenesis, suggesting a positive effect of low oxygen found in fracture hematoma as a guide for MSC differentiation trigger for osteogenesis and bone healing [61]. In our system, the level of mineralization appeared to be independent of oxygen tension, since we observed a similar Von Kossa and collagen type I staining for the groups differentiated under $2 \%$ and $20 \% \mathrm{O}_{2}$. We assume that the discrepancies between our study and previous studies could be due to the oxygen concentration used during the expansion process, to the variety of MSCs species/sources used and to the choice of 3D or 2D environments in pellet or scaffold cultures. In particular, material-based differences might play a role. In our study, we investigated hMSCs, expanded under $20 \%$ $\mathrm{O}_{2}$ and differentiated within 3D fibrin constructs under low and high oxygen. Although it is still challenging to make broad conclusions regarding the role of oxygen on MSC biology, our study indicates that low oxygen is beneficial for chondrogenic differentiation but had little effect on osteogenic differentiation at the protein level. The lack of changes in HIF1 $\alpha$ expression makes full interpretation of the data difficult, however the consistency of the changes suggest a HIF $1 \alpha$ independent mechanism may be involved. The easy modulation of the oxygen tension in the in vitro studies make this a parameter that can be tailored to either stabilize a chondrogenic phenotype under low oxygen for use in cartilage repair therapies or to promote endochondral bone repair strategies under medium to high oxygen through the induction of the hypertrophy of cartilaginous grafts.

This study is not without limitations, while it is an advantage to study individual donors, the donor variation suggests studies with primary human cells may need more than the four donors used here. While that is an ideal scenario, it is demanding due to the large number of groups and cell number requirements involved. This also influenced the decision to perform one time point, as additional time points would lead to unfeasible cell numbers being required. A more detailed protein analysis of the conditioned media by way of ELISA may also provide a more detailed insight into the relative matrix retention rates. However, as a proof of concept this study does demonstrate the feasibility of such 
an approach. Also, the two-week culture period only allows for investigation into early events. As previous studies have shown that early events are key in the differentiation pathway $[62,63]$, we believe that longer-term studies would strengthen the conclusions. Furthermore, a future step would be to co-culture pre-differentiated scaffolds to allow for tissue cross-talk, with the aim to enhance tissue formation. A further development of the system would be to culture the cells under osteogenic and chondrogenic conditions for two weeks, and then combine the scaffolds for a further two weeks with direct contact. This would allow for cross-talk studies to investigate if the cells at different differentiation states interact by way of soluble signals to further regulate tissue maturation. Due to the asymmetrically seeded cartilage layer, combination with an osteogenically induced base layer would lead to a tri-layered structure that loosely mimics an osteochondral plug. In case of clinical implantation, the two constructs could be attached using fibrin glue or be held in place using a subchondral bone anchor, thereby providing a pre-differentiated bilayer scaffold for osteochondral repair.

Author Contributions: Conceptualization, M.A. and M.J.S.; Data curation, G.M. and Y.D.L.; Formal analysis, G.M. and Y.D.L.; Funding acquisition, M.A. and M.J.S.; Investigation, M.J.S.; Methodology, G.M.; Resources, N.R.F.; Supervision, A.J.E.H., N.R.F. and M.A.; Writing—original draft, G.M., A.J.E.H., N.R.F. and M.J.S.; Writing—review \& editing, G.M., Y.D.L., A.J.E.H., M.A. and M.J.S. All authors have read and agreed to the published version of the manuscript.

Funding: This research was funded by the AO Foundation and the Swiss National Science Foundation, grant number 31003A_179438.

Institutional Review Board Statement: The study was conducted according to the guidelines of the Declaration of Helsinki, and approved by the Institutional Review Board (or Ethics Committee) of the Canton of Zürich (KEK-ZH-NR: 2010-0444/0 on 04.01.2011).

Informed Consent Statement: Signed informed consent was obtained from all subjects involved in the study.

Data Availability Statement: Data is contained within the article. More detailed data can be provided upon reasonable request.

Conflicts of Interest: The authors declare no conflict of interest.

\section{References}

1. Kurtz, S.; Ong, K.; Lau, E.; Mowat, F.; Halpern, M. Projections of primary and revision hip and knee arthroplasty in the United States from 2005 to 2030. JBJS 2007, 89, 780-785. [CrossRef]

2. Madry, H.; Grün, U.W.; Knutsen, G. Cartilage repair and joint preservation: Medical and surgical treatment options. Dtsch. Ärzteblatt Int. 2011, 108, 669.

3. Marcacci, M.; Filardo, G.; Kon, E. Treatment of cartilage lesions: What works and why? Injury 2013, 44, S11-S15. [CrossRef]

4. Michael, J.; Schlüter-Brust, K.U.; Eysel, P. The epidemiology, etiology, diagnosis, and treatment of osteoarthritis of the knee. Dtsch. Arztebl. Int. 2010, 107, 152-162. [CrossRef] [PubMed]

5. Hangody, L.; Füles, P. Autologous osteochondral mosaicplasty for the treatment of full-thickness defects of weight-bearing joints: Ten years of experimental and clinical experience. JBJS 2003, 85, 25-32. [CrossRef]

6. Tetta, C.; Busacca, M.; Moio, A.; Rinaldi, R.; Delcogliano, M.; Kon, E.; Filardo, G.; Marcacci, M.; Albisinni, U. Knee osteochondral autologous transplantation: Long-term MR findings and clinical correlations. Eur. J. Radiol. 2010, 76, 117-123. [CrossRef]

7. Brittberg, M. Autologous chondrocyte implantation-Technique and long-term follow-up. Injury 2008, 39, 40-49. [CrossRef]

8. Kon, E.; Verdonk, P.; Condello, V.; Delcogliano, M.; Dhollander, A.; Filardo, G.; Pignotti, E.; Marcacci, M. Matrix-assisted autologous chondrocyte transplantation for the repair of cartilage defects of the knee: Systematic clinical data review and study quality analysis. Am. J. Sports Med. 2009, 37, 156-166. [CrossRef]

9. Barone, D.J.; Raquez, J.M.; Dubois, P. Bone-guided regeneration: From inert biomaterials to bioactive polymer (nano) composites. Polym. Adv. Technol. 2011, 22, 463-475. [CrossRef]

10. Martin, I.; Miot, S.; Barbero, A.; Jakob, M.; Wendt, D. Osteochondral tissue engineering. J. Biomech. 2007, 40, 750-765. [CrossRef]

11. Lam, J.; Lu, S.; Meretoja, V.V.; Tabata, Y.; Mikos, A.G.; Kasper, F.K. Generation of osteochondral tissue constructs with chondrogenically and osteogenically predifferentiated mesenchymal stem cells encapsulated in bilayered hydrogels. Acta Biomater. 2014, 10, 1112-1123. [CrossRef]

12. Mauck, R.L.; Nicoll, S.B.; Seyhan, S.L.; Ateshian, G.A.; Hung, C.T. Synergistic action of growth factors and dynamic loading for articular cartilage tissue engineering. Tissue Eng. 2003, 9, 597-611. [CrossRef] 
13. Wang, Y.; Blasioli, D.J.; Kim, H.-J.; Kim, H.S.; Kaplan, D.L. Cartilage tissue engineering with silk scaffolds and human articular chondrocytes. Biomaterials 2006, 27, 4434-4442. [CrossRef]

14. Pittenger, M.F.; Mackay, A.M.; Beck, S.C.; Jaiswal, R.K.; Douglas, R.; Mosca, J.D.; Moorman, M.A.; Simonetti, D.W.; Craig, S.; Marshak, D.R. Multilineage potential of adult human mesenchymal stem cells. Science 1999, 284, 143-147. [CrossRef]

15. de Vries-van Melle, M.L.; Tihaya, M.S.; Kops, N.; Koevoet, W.; Murphy, J.M.; Verhaar, J.; Alini, M.; Eglin, D.; van Osch, G. Chondrogenic differentiation of human bone marrow-derived mesenchymal stem cells in a simulated osteochondral environment is hydrogel dependent. Eur. Cell Mater. 2014, 27, 112-123. [CrossRef]

16. Wakitani, S.; Imoto, K.; Yamamoto, T.; Saito, M.; Murata, N.; Yoneda, M. Human autologous culture expanded bone marrow mesenchymal cell transplantation for repair of cartilage defects in osteoarthritic knees. Osteoarthr. Cartil. 2002, 10, 199-206. [CrossRef]

17. Nejadnik, H.; Hui, J.H.; Feng Choong, E.P.; Tai, B.-C.; Lee, E.H. Autologous bone marrow-derived mesenchymal stem cells versus autologous chondrocyte implantation: An observational cohort study. Am. J. Sports Med. 2010, 38, 1110-1116. [CrossRef] [PubMed]

18. Herrmann, M.; Hildebrand, M.; Menzel, U.; Fahy, N.; Alini, M.; Lang, S.; Benneker, L.; Verrier, S.; Stoddart, M.J.; Bara, J.J. Phenotypic characterization of bone marrow mononuclear cells and derived stromal cell populations from human iliac crest, vertebral body and femoral head. Int. J. Mol. Sci. 2019, 20, 3454. [CrossRef] [PubMed]

19. Halleux, C.; Sottile, V.; Gasser, J.; Seuwen, K. Multi-lineage potential of human mesenchymal stem cells following clonal expansion. J. Musculoskelet. Neuronal Interact. 2001, 2,71-76. [PubMed]

20. Wakitani, S.; Goto, T.; Pineda, S.J.; Young, R.G.; Mansour, J.M.; Caplan, A.I.; Goldberg, V.M. Mesenchymal cell-based repair of large, full-thickness defects of articular cartilage. JBJS 1994, 76, 579-592. [CrossRef]

21. Mauney, J.R.; Volloch, V.; Kaplan, D.L. Role of adult mesenchymal stem cells in bone tissue engineering applications: Current status and future prospects. Tissue Eng. 2005, 11, 787-802. [CrossRef] [PubMed]

22. $\mathrm{Ng}$, J.; Bernhard, J.; Vunjak-Novakovic, G. Mesenchymal stem cells for osteochondral tissue engineering. In Mesenchymal Stem Cells; Springer: New York, NY, USA, 2016; pp. 35-54.

23. Larson, B.L.; Yu, S.N.; Park, H.; Estes, B.T.; Moutos, F.T.; Bloomquist, C.J.; Wu, P.B.; Welter, J.F.; Langer, R.; Guilak, F. Chondrogenic, hypertrophic, and osteochondral differentiation of human mesenchymal stem cells on three-dimensionally woven scaffolds. $J$. Tissue Eng. Regen. Med. 2019, 13, 1453-1465. [CrossRef] [PubMed]

24. Goldring, M.B.; Tsuchimochi, K.; Ijiri, K. The control of chondrogenesis. J. Cell. Biochem. 2006, 97, 33-44. [CrossRef] [PubMed]

25. Mueller, M.B.; Fischer, M.; Zellner, J.; Berner, A.; Dienstknecht, T.; Prantl, L.; Kujat, R.; Nerlich, M.; Tuan, R.S.; Angele, P. Hypertrophy in mesenchymal stem cell chondrogenesis: Effect of TGF- $\beta$ isoforms and chondrogenic conditioning. Cells Tissues Organs 2010, 192, 158-166. [CrossRef]

26. Mackie, E.J.; Tatarczuch, L.; Mirams, M. The skeleton: A multi-functional complex organ. The growth plate chondrocyte and endochondral ossification. J. Endocrinol. 2011, 211, 109-121. [CrossRef] [PubMed]

27. Pattappa, G.; Johnstone, B.; Zellner, J.; Docheva, D.; Angele, P. The importance of physioxia in mesenchymal stem cell chondrogenesis and the mechanisms controlling its response. Int. J. Mol. Sci. 2019, 20, 484. [CrossRef]

28. Sheehy, E.J.; Buckley, C.T.; Kelly, D.J. Oxygen tension regulates the osteogenic, chondrogenic and endochondral phenotype of bone marrow derived mesenchymal stem cells. Biochem. Biophys. Res. Commun. 2012, 417, 305-310. [CrossRef] [PubMed]

29. Kay, A.; Richardson, J.; Forsyth, N.R. Physiological normoxia and chondrogenic potential of chondrocytes. Front Biosci 2011, 3, 1365-1374. [CrossRef]

30. Nichols, D.A.; Sondh, I.S.; Litte, S.R.; Zunino, P.; Gottardi, R. Design and validation of an osteochondral bioreactor for the screening of treatments for osteoarthritis. Biomed. Microdevices 2018, 20, 18. [CrossRef]

31. Johnstone, B.; Hering, T.M.; Caplan, A.I.; Goldberg, V.M.; Yoo, J.U. In vitrochondrogenesis of bone marrow-derived mesenchymal progenitor cells. Exp. Cell Res. 1998, 238, 265-272. [CrossRef]

32. Gasser, J.A.; Kneissel, M. Bone physiology and biology. In Bone Toxicology; Springer: New York, NY, USA, 2017 ; pp. 27-94.

33. Gorna, K.; Gogolewski, S. In vitro degradation of novel medical biodegradable aliphatic polyurethanes based on $\epsilon$-caprolactone and Pluronics ${ }^{\circledR}$ with various hydrophilicities. Polym. Degrad. Stab. 2002, 75, 113-122. [CrossRef]

34. Li, Z.; Kupcsik, L.; Yao, S.-J.; Alini, M.; Stoddart, M.J. Chondrogenesis of human bone marrow mesenchymal stem cells in fibrin-polyurethane composites. Tissue Eng. Part A 2008, 15, 1729-1737. [CrossRef] [PubMed]

35. Gardner, O.F.; Musumeci, G.; Neumann, A.J.; Eglin, D.; Archer, C.W.; Alini, M.; Stoddart, M.J. Asymmetrical seeding of MSCs into fibrin-poly (ester-urethane) scaffolds and its effect on mechanically induced chondrogenesis. J. Tissue Eng. Regen. Med. 2017, 11, 2912-2921. [CrossRef]

36. Labarca, C.; Paigen, K. A simple, rapid, and sensitive DNA assay procedure. Anal. Biochem. 1980, 102, 344-352. [CrossRef]

37. Farndale, R.W.; Buttle, D.J.; Barrett, A.J. Improved quantitation and discrimination of sulphated glycosaminoglycans by use of dimethylmethylene blue. Biochim. Biophys. Acta (BBA)-Gen. Subj. 1986, 883, 173-177. [CrossRef]

38. Marupanthorn, K.; Tantrawatpan, C.; Kheolamai, P.; Tantikanlayaporn, D.; Manochantr, S. Bone morphogenetic protein-2 enhances the osteogenic differentiation capacity of mesenchymal stromal cells derived from human bone marrow and umbilical cord. Int. J. Mol. Med. 2017, 39, 654-662. [CrossRef] [PubMed]

39. Bieback, K.; Kinzebach, S.; Karagianni, M. Translating research into clinical scale manufacturing of mesenchymal stromal cells. Stem Cells Int. 2011, 2010, 193519. [CrossRef] 
40. Schneider, C.K.; Salmikangas, P.; Jilma, B.; Flamion, B.; Todorova, L.R.; Paphitou, A.; Haunerova, I.; Maimets, T.; Trouvin, J.-H.; Flory, E.; et al. Challenges with advanced therapy medicinal products and how to meet them. Nat. Rev. Drug Discov. $2010,9,195$. [PubMed]

41. Pattappa, G.; Schewior, R.; Hofmeister, I.; Seja, J.; Zellner, J.; Johnstone, B.; Docheva, D.; Angele, P. Physioxia has a beneficial effect on cartilage matrix production in interleukin-1 beta-inhibited mesenchymal stem cell chondrogenesis. Cells $2019,8,936$. [CrossRef]

42. Pelttari, K.; Winter, A.; Steck, E.; Goetzke, K.; Hennig, T.; Ochs, B.G.; Aigner, T.; Richter, W. Premature induction of hypertrophy during in vitro chondrogenesis of human mesenchymal stem cells correlates with calcification and vascular invasion after ectopic transplantation in SCID mice. Arthritis Rheum. Off. J. Am. Coll. Rheumatol. 2006, 54, 3254-3266. [CrossRef]

43. Zhu, M.; Feng, Q.; Bian, L. Differential effect of hypoxia on human mesenchymal stem cell chondrogenesis and hypertrophy in hyaluronic acid hydrogels. Acta Biomater. 2014, 10, 1333-1340. [CrossRef]

44. Henrionnet, C.; Liang, G.; Roeder, E.; Dossot, M.; Wang, H.; Magdalou, J.; Gillet, P.; Pinzano, A. Hypoxia for mesenchymal stem cell expansion and differentiation: The best way for enhancing TGFß-induced chondrogenesis and preventing calcifications in alginate beads. Tissue Eng. Part A 2017, 23, 913-922. [CrossRef] [PubMed]

45. Sharma, U.; Pal, D.; Prasad, R. Alkaline phosphatase: An overview. Indian J. Clin. Biochem. 2014, 29, 269-278. [CrossRef] [PubMed]

46. Anderson, D.E.; Markway, B.D.; Bond, D.; McCarthy, H.E.; Johnstone, B. Responses to altered oxygen tension are distinct between human stem cells of high and low chondrogenic capacity. Stem Cell Res. Ther. 2016, 7, 154. [CrossRef] [PubMed]

47. Leijten, J.; Georgi, N.; Teixeira, L.M.; van Blitterswijk, C.A.; Post, J.N.; Karperien, M. Metabolic programming of mesenchymal stromal cells by oxygen tension directs chondrogenic cell fate. Proc. Natl. Acad. Sci. USA 2014, 111, 13954-13959. [CrossRef]

48. Meretoja, V.V.; Dahlin, R.L.; Wright, S.; Kasper, F.K.; Mikos, A.G. The effect of hypoxia on the chondrogenic differentiation of co-cultured articular chondrocytes and mesenchymal stem cells in scaffolds. Biomaterials 2013, 34, 4266-4273. [CrossRef]

49. Müller, J.; Benz, K.; Ahlers, M.; Gaissmaier, C.; Mollenhauer, J. Hypoxic conditions during expansion culture prime human mesenchymal stromal precursor cells for chondrogenic differentiation in three-dimensional cultures. Cell Transplant. 2011, 20, 1589-1602. [CrossRef] [PubMed]

50. Anderson, D.E.; Markway, B.D.; Weekes, K.J.; McCarthy, H.E.; Johnstone, B. Physioxia promotes the articular chondrocyte-like phenotype in human chondroprogenitor-derived self-organized tissue. Tissue Eng. Part A 2018, 24, 264-274. [CrossRef]

51. Rodenas-Rochina, J.; Kelly, D.J.; Gómez Ribelles, J.L.; Lebourg, M. Influence of oxygen levels on chondrogenesis of porcine mesenchymal stem cells cultured in polycaprolactone scaffolds. J. Biomed. Mater. Res. Part A 2017, 105, 1684-1691. [CrossRef]

52. Bae, H.C.; Park, H.J.; Wang, S.Y.; Yang, H.R.; Lee, M.C.; Han, H.-S. Hypoxic condition enhances chondrogenesis in synoviumderived mesenchymal stem cells. Biomater. Res. 2018, 22, 1-8. [CrossRef]

53. Pilgaard, L.; Lund, P.; Duroux, M.; Lockstone, H.; Taylor, J.; Emmersen, J.; Fink, T.; Ragoussis, J.; Zachar, V. Transcriptional signature of human adipose tissue-derived stem cells (hASCs) preconditioned for chondrogenesis in hypoxic conditions. Exp. Cell Res. 2009, 315, 1937-1952. [CrossRef] [PubMed]

54. Portron, S.; Hivernaud, V.; Merceron, C.; Lesoeur, J.; Masson, M.; Gauthier, O.; Vinatier, C.; Beck, L.; Guicheux, J. Inverse regulation of early and late chondrogenic differentiation by oxygen tension provides cues for stem cell-based cartilage tissue engineering. Cell. Physiol. Biochem. 2015, 35, 841-857. [CrossRef] [PubMed]

55. Yoo, J.U.; Barthel, T.S.; Nishimura, K.; Solchaga, L.; Caplan, A.I.; Goldberg, V.M.; Johnstone, B. The chondrogenic potential of human bone-marrow-derived mesenchymal progenitor cells. JBJS 1998, 80, 1745-1757. [CrossRef] [PubMed]

56. Monaco, G.; El Haj, A.J.; Alini, M.; Stoddart, M.J. Sodium hyaluronate supplemented culture media as a new hMSC chondrogenic differentiation media-model for in vitro/ex vivo screening of potential cartilage repair therapies. Front. Bioeng. Biotechnol. 2020, 8, 243. [CrossRef]

57. Stoddart, M.J.; Richards, R.; Alini, M. In vitro experiments with primary mammalian cells: To pool or not to pool. Eur. Cell Mater. 2012, 24, i-ii. [CrossRef]

58. Pattappa, G.; Thorpe, S.D.; Jegard, N.C.; Heywood, H.K.; de Bruijn, J.D.; Lee, D.A. Continuous and uninterrupted oxygen tension influences the colony formation and oxidative metabolism of human mesenchymal stem cells. Tissue Eng. Part C Methods 2013, 19, 68-79. [CrossRef]

59. Munir, S.; Foldager, C.B.; Lind, M.; Zachar, V.; Søballe, K.; Koch, T.G. Hypoxia enhances chondrogenic differentiation of human adipose tissue-derived stromal cells in scaffold-free and scaffold systems. Cell Tissue Res. 2014, 355, 89-102. [CrossRef]

60. Holzwarth, C.; Vaegler, M.; Gieseke, F.; Pfister, S.M.; Handgretinger, R.; Kerst, G.; Müller, I. Low physiologic oxygen tensions reduce proliferation and differentiation of human multipotent mesenchymal stromal cells. BMC Cell Biol. 2010, 11, 11. [CrossRef]

61. Wagegg, M.; Gaber, T.; Lohanatha, F.L.; Hahne, M.; Strehl, C.; Fangradt, M.; Tran, C.L.; Schönbeck, K.; Hoff, P.; Ode, A.; et al. Hypoxia promotes osteogenesis but suppresses adipogenesis of human mesenchymal stromal cells in a hypoxia-inducible factor-1 dependent manner. PLoS ONE 2012, 7, e46483. [CrossRef]

62. Loebel, C.; Czekanska, E.M.; Bruderer, M.; Salzmann, G.; Alini, M.; Stoddart, M.J. In vitro osteogenic potential of human mesenchymal stem cells is predicted by Runx2/Sox9 ratio. Tissue Eng. Part A 2015, 21, 115-123. [CrossRef]

63. Rothweiler, R.; Basoli, V.; Duttenhoefer, F.; Kubosch, D.; Schmelzeisen, R.; Johnstone, B.; Alini, M.; Stoddart, M.J. Predicting and promoting human bone marrow MSC chondrogenesis by way of TGF $\beta$ receptor profiles: Toward personalized medicine. Front. Bioeng. Biotechnol. 2020, 8, 618. [CrossRef] [PubMed] 